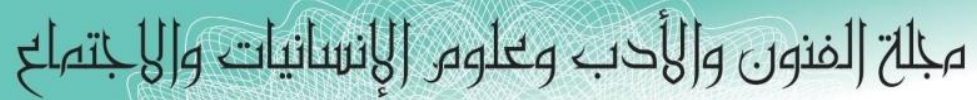

Journal of Arts, Literature, Humanities and Social Sciences

ISSN online: 2414 - 3383

ISSN print: 2616 - 3810
العدد (44) أكتوبر 2019

Volume (44) October 2019
¿ALLHSS WWW.jalhss.com

\title{
مفهوم عمل أهل المدينة في الثريعة الإسلامية
}

د.مجيا سعيد حمه صالح

الملخص

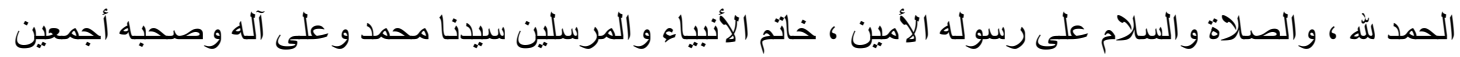

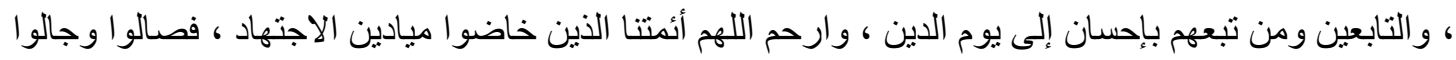

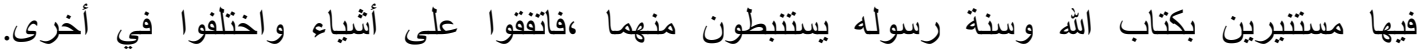

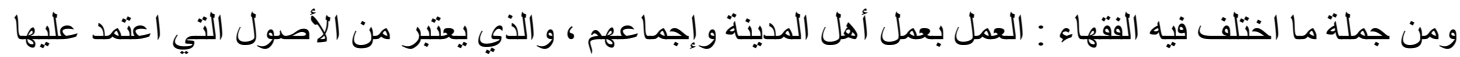

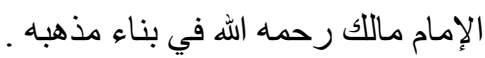
و هذا الأصل المختلف فيه له نأثير في الفروع الفقهية ، وبعض الأحكام التي نشأ فيها الخلاف نتيجة للعمل بهذا

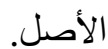

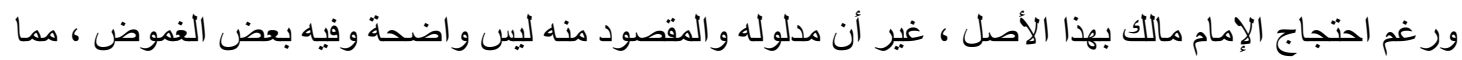

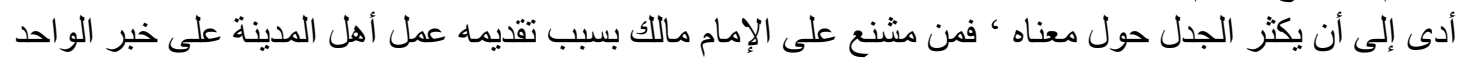

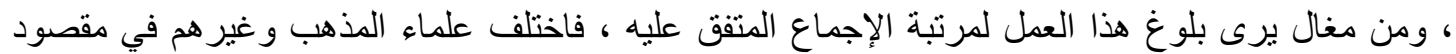

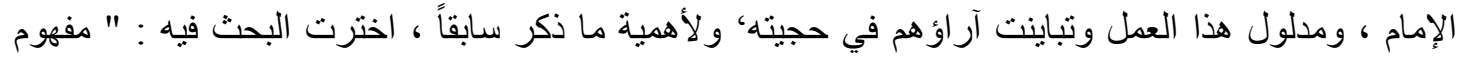

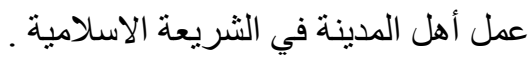

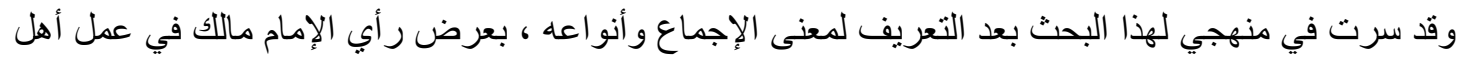

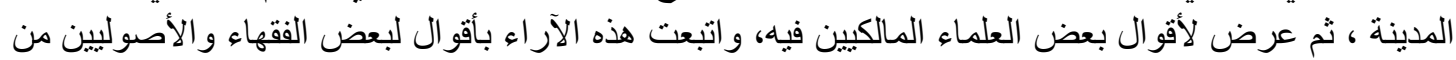

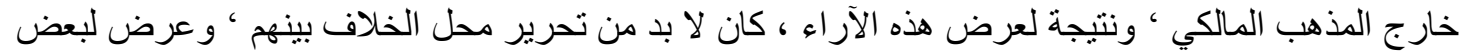

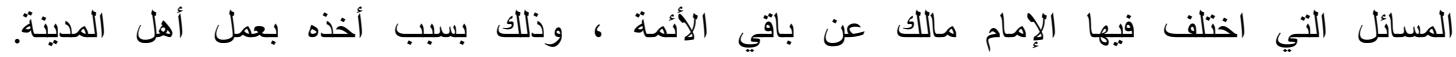

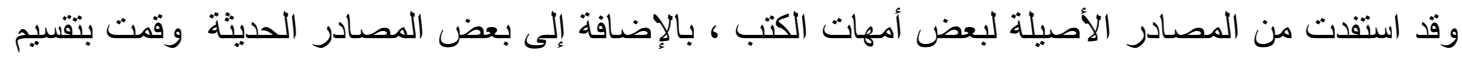
البحث إلى تمهيد ومقدمة وفصلين وخاتمة. 


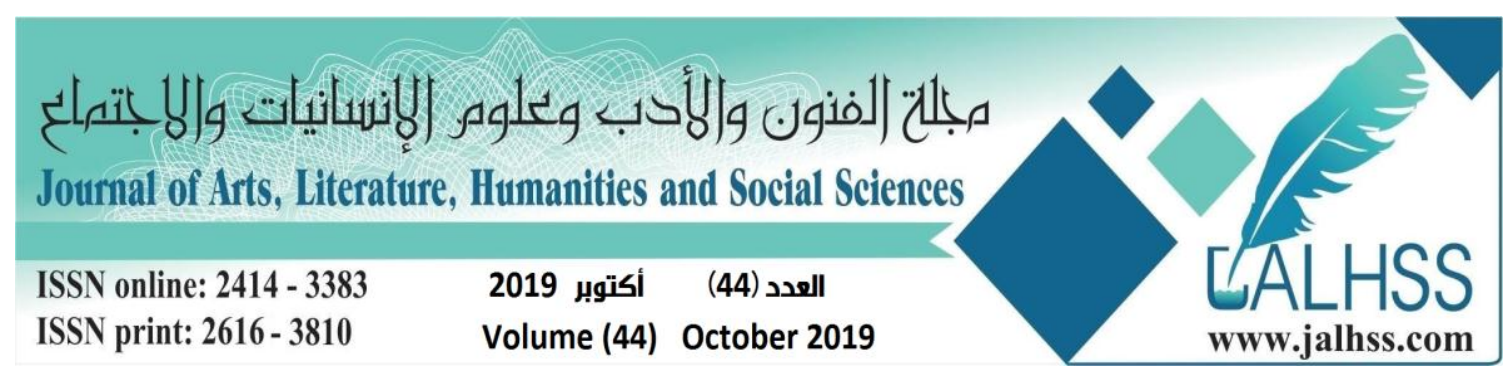

\title{
The Concept of The Work of The People of The City in Islamic Law
}

\author{
Majeed Saeed Hama Salih
}

\begin{abstract}
Praise be to God, and peace and blessings be upon His faithful Messenger, the seal of the prophets and messengers of our Prophet Muhammad and his family and companions. Other.

Among the various scholars who disagree: Work the work of the people of the city and their unanimity, which is one of the assets on which Imam Malik, may God have mercy on him, in building his doctrine.

This difference in origin has an impact on the jurisprudential branches, and some provisions in which the dispute arose as a result of the work of this original. Despite the protest of Imam Malik, but the meaning and meaning of it is not clear and there is some ambiguity, which led to the controversy abound about its meaning 'It is outrageous to Imam Malik because of the work of the people of the city on the news of one, and Magal believes that this work to reach the rank of consensus accordingly, scholars differed doctrine and others in the intent of the Imam, and the significance of this work and their opinions differed in his argument 'and the importance of what was mentioned earlier, I chose to search it: "The concept of the work of the people of the city in Islamic law.

I have walked in the methodology of this research after the definition of the meaning and types of consensus, by the view of Imam Malik in the work of the people of the city, and then introduced the words of some scholars Maliki, and followed these views with some scholars and fundamentalists from outside the Maliki school 'As a result of the presentation of these views, it was necessary to Liberation of the dispute between them 'and introduced to some of the issues where the imam Malik differed from the rest of the imams, because of taking the work of the people of the city. I have benefited from the original sources of some books mothers, in addition to some modern sources and I divided the research into a preface, introduction, two chapters and a conclusion.
\end{abstract}




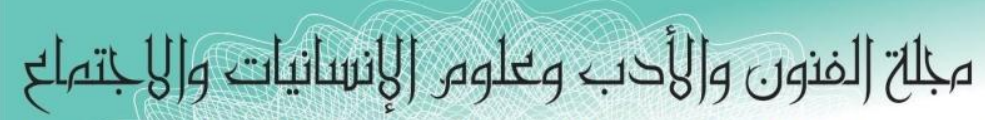

Journal of Arts, Literature, Humanities and Social Sciences

ISSN online: 2414 - 3383

ISSN print: 2616 - 3810

$\begin{array}{lc}2019 \text { أكتوبر } 2019 & \text { (44) } \\ \text { Volume (44) } & \text { October } 2019\end{array}$

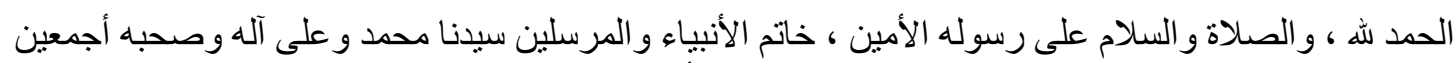

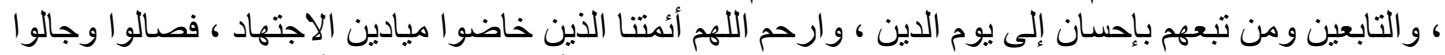

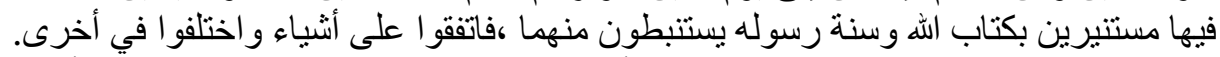
ومن جملة ما اختلف فيه الفقهاء : العمل بعمل أهل المدينة و إجماعهم ، و الذي يعتئ ولنير من الأصول التي اعتمد عليها الإمام مالك رحمه الله في بناء مذهبه.

و هذا الأصل المختلف فيه له ناثير في الفروع الفقهية ، وبعض الأحكام التي نشا فيها الخلاف نتيجة للعمل بهذا

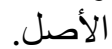

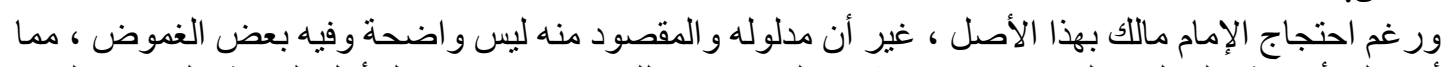

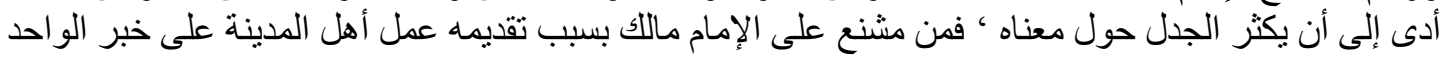

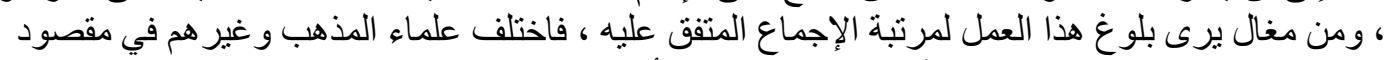

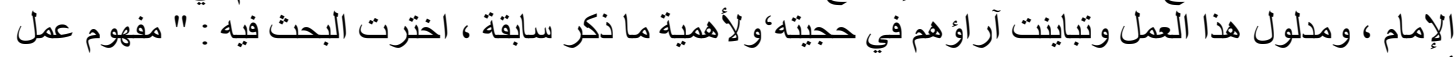
أهل المدينة ، في الثريعة الإسلامية.

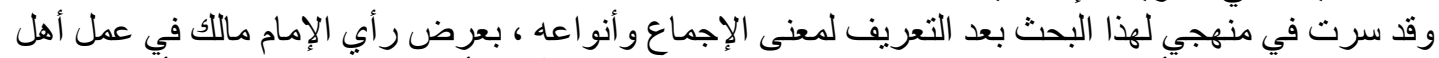

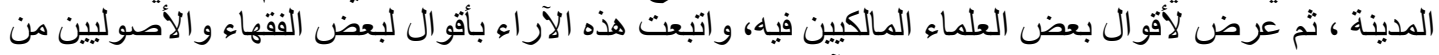

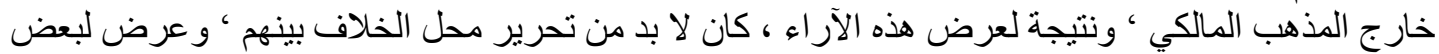

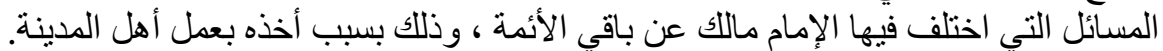
وقد استفدت من المصادر الأصيلة لبعض أمهات الكتب ، بالإضافة إلى بعض المضات المصادر الحديثة وقمت بتقسيم

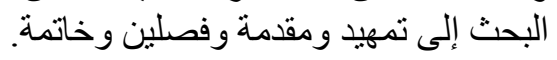
التمهيد ، وذكرت فيه نبذة مختصرة وفئ عن الإمام مالك ، ثم المقدة.

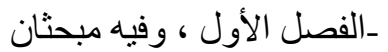

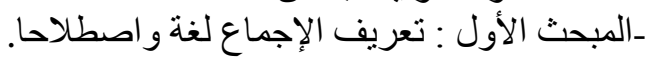

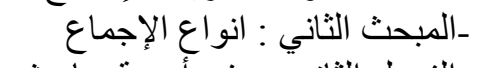
ـالفصل الثاني ، وانيه : الثبه أربعة مباحث: الإعماع:

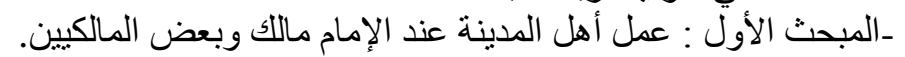

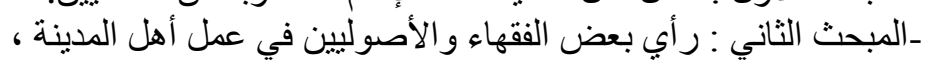

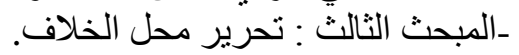

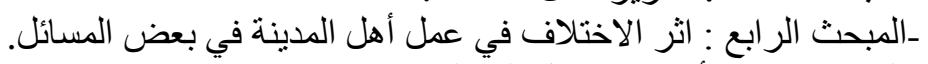

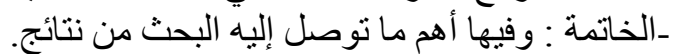
آمل أن أكون ق قد وفقت في إعداد هذا البحث ، و والحمد لله من قبل ومن بعد.

\section{التمهيد \\ نبذة عن إمام دار الهجرة "مالكاد}

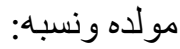

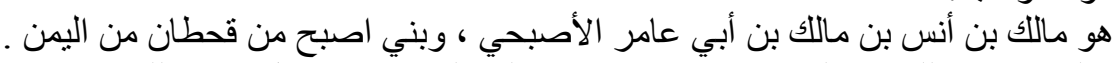

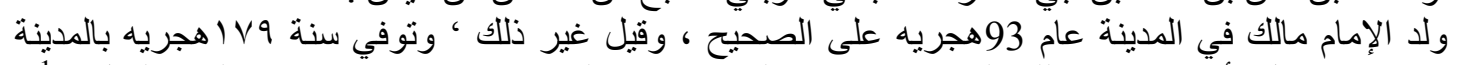

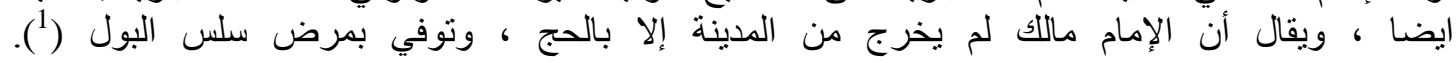
نشاته

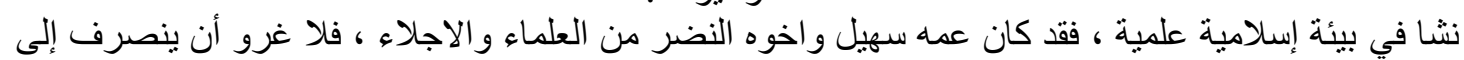

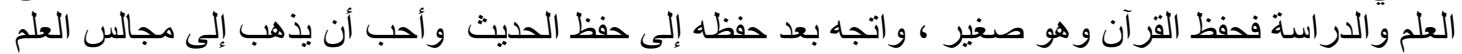
فثجعته أسرته وخاصة أمه التي البسته أحسن الثياب و عممته وقالت لـ اله:

-1 ينظر : ترتيب المدارك للقاضي عياض . ص 112-104 - مالك لأبي زهرة •ص8وما بعدها. 


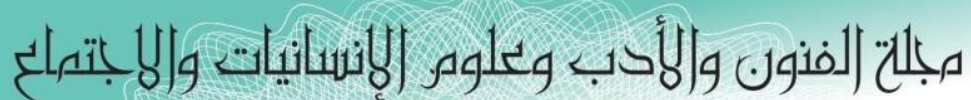

Journal of Arts, Literature, Humanities and Social Sciences

ISSN online: 2414 - 3383

ISSN print: 2616 - 3810

\section{العدد (44) أكتوبر 2019 \\ Volume (44) October 2019}

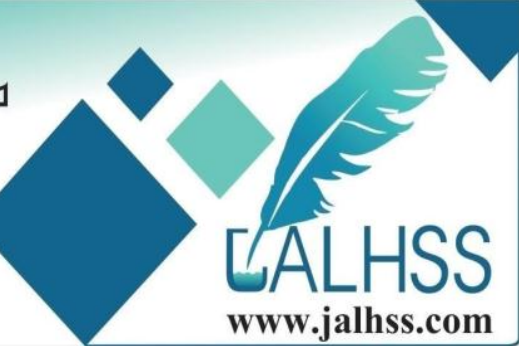

WWW.jalhss.com

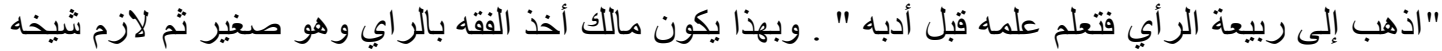

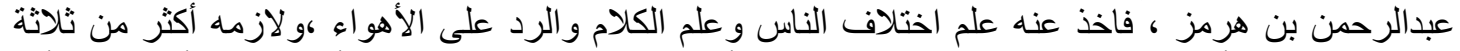

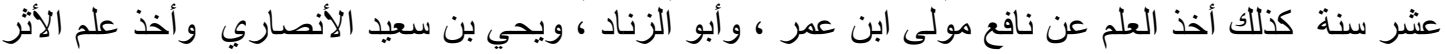

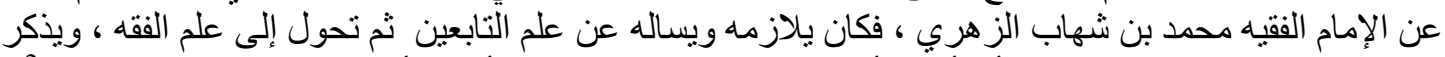
في سبب انصر افه إلى ذلك ، هو أن أباه سأله عن حكم مسالة فم يجب و وأجاب أخوه ، فانصرف الته إلى الفقه (2). فتباه

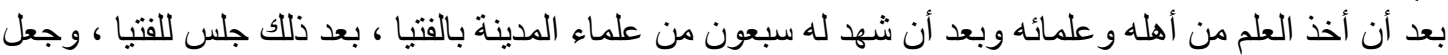

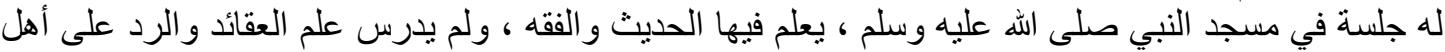

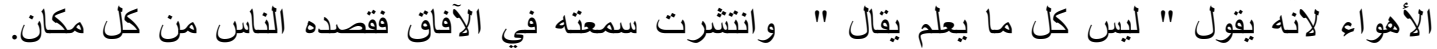

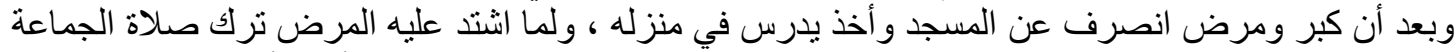

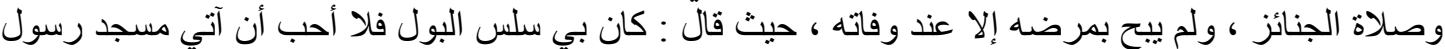

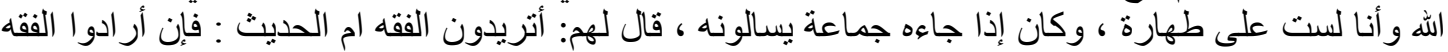

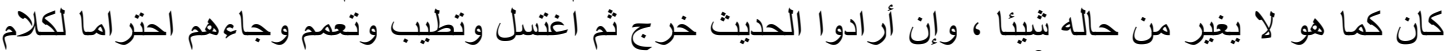

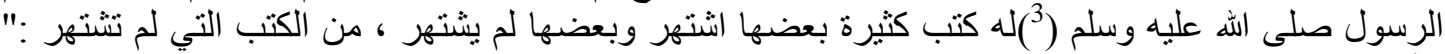

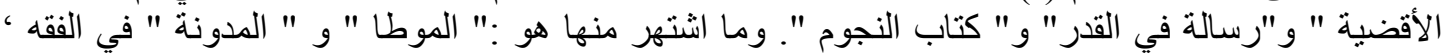

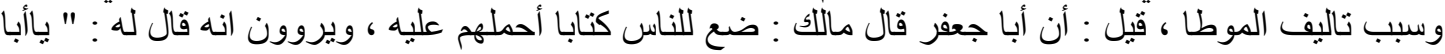

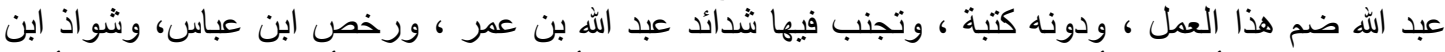

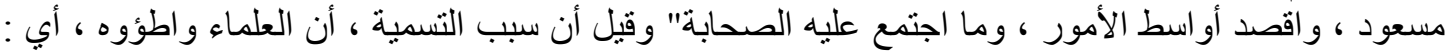

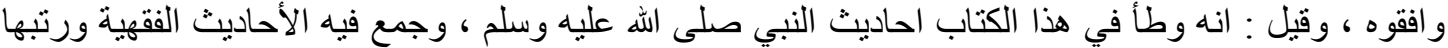

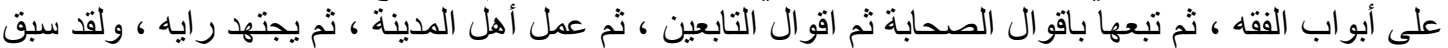

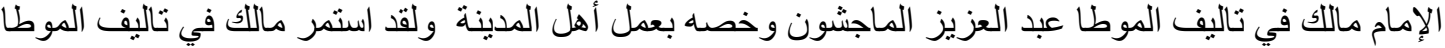

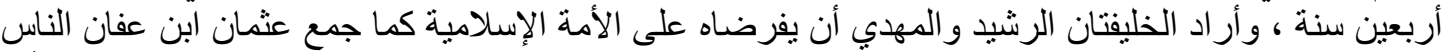

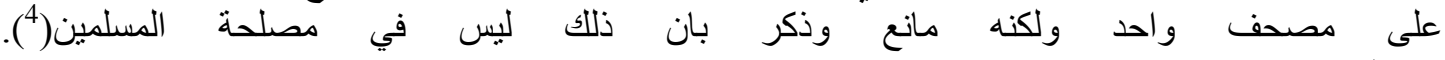

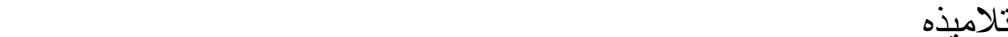

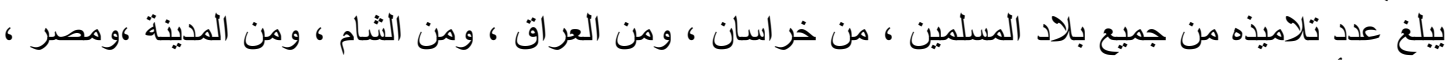

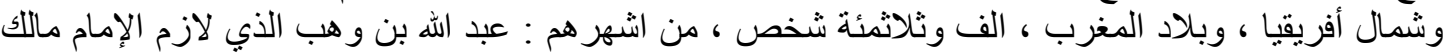

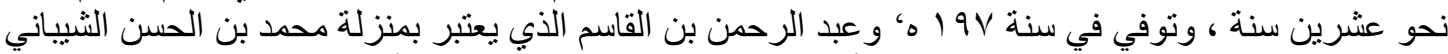

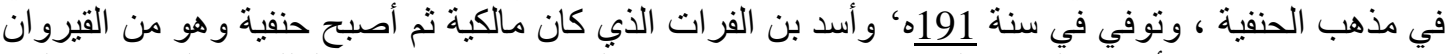

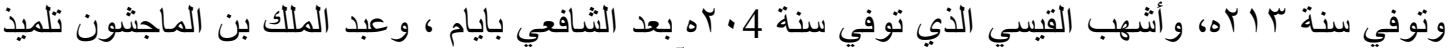

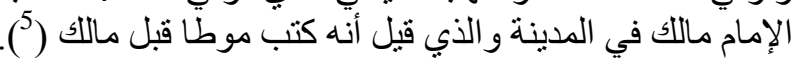

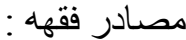

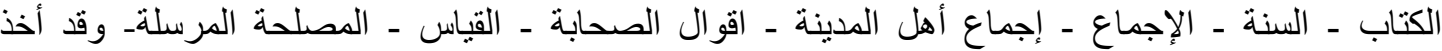
بالاستحسان ، و الاستصحاب ، وسد الذرائع - و المقصود بعمل أهل المدينة : ما عليه أهل المدينة في زمن الإلة الإمام

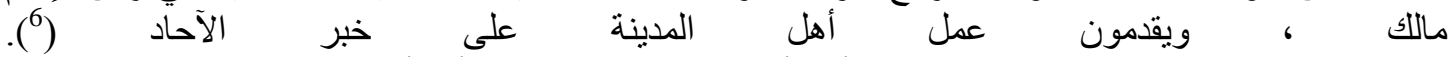

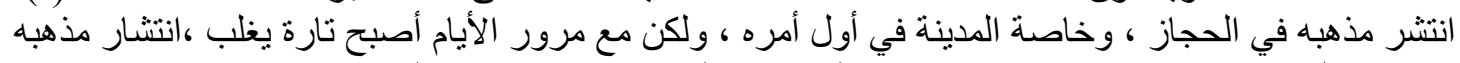

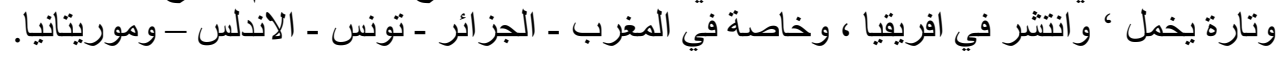

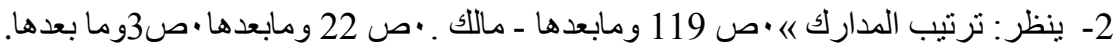

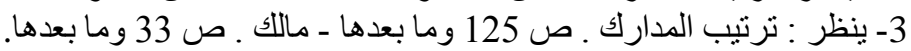

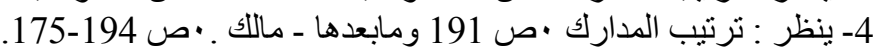

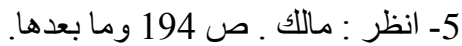

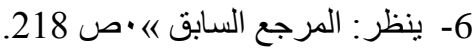




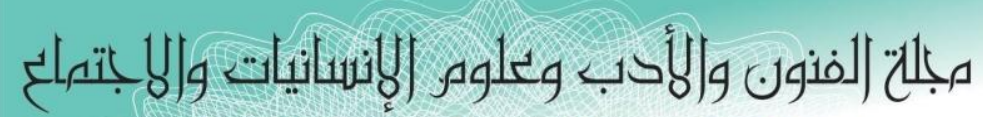

Journal of Arts, Literature, Humanities and Social Sciences

ISSN online: 2414 - 3383

ISSN print: 2616 - 3810

$\begin{array}{lc}2019 \text { أكتوبر } 2019 & \text { (44) } \\ \text { Volume (44) } & \text { October } 2019\end{array}$

¿ÁLHSS www.jalhss.com

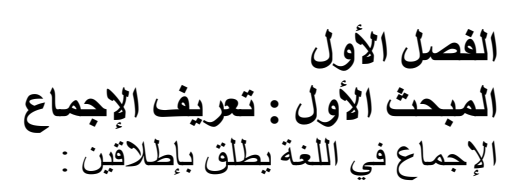

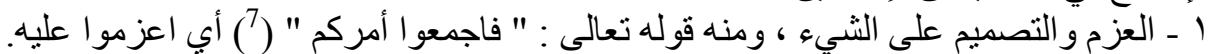

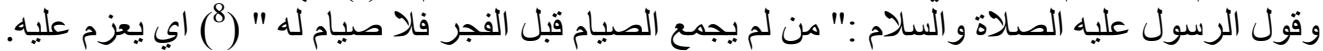

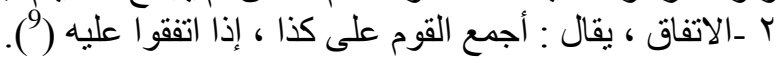

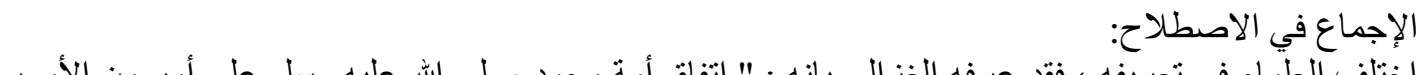
اختلف العلمّاء في تعريفه ، فقد عرفه الغزاح الي بانه : " اتفاق أمة محمد صلى الله عليه وسلم على أمر من الأمور

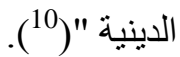
و عرفه الآمدي بانه " اتفاق جملة من أهل الحل و العقد من أمة محمد صلى الله عليه وسلم في عصر من الأعصار

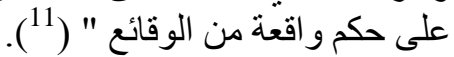
و عرفه الثوكاني :"اتفاق مجتهدي المة محت محد صلى الله عليه وسلم بعد وفاته في عصر من الأعمار على أمر من

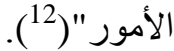
و المر اد بالاتفاق ، الإشتر الك في قول أو فعل أو اعتقاد.

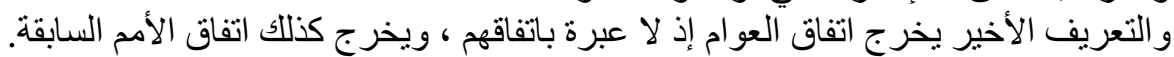

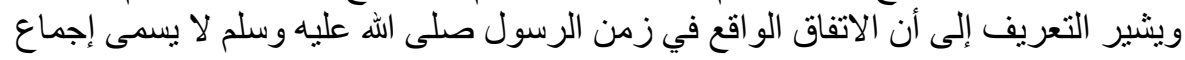

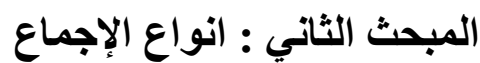
القسم الأول ، بالنظر إلى كيفية حدوثه ووقو عالِه ( الإجماع العام).

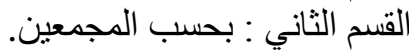

القسم الأول : الإجماع العام

ومنه الإجماع الصريح القولي : وهو حجة عند الجمهور ، ويعتبر المصدر الثالث من مصادر

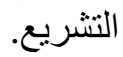
ومن هذا القسم : الإجماع السكوتي ، وهو أن يبدي بعض المجتهدين رايهم في حكم شرعي أو مسالة ويسكت الباقون (13) (13) وقد اشترط القائلون بحجيته (الحنفية والحنابلة ) شروطأ لا بد من توفر ها فيه حتى يحقق معنى الإجماع (14)،

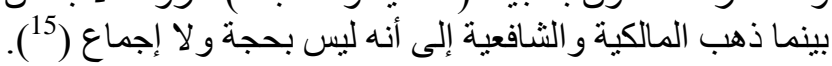
القسم الثاني : بحسب المجمعين المئل

7- سورة يونس الآية71. 8- ينظر: سنن الدار قطني ـ 2/172 - فتح الباري شرح صحيح البخاري ـ ابن حجر ؛ ج 4 .ص 142

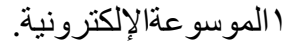

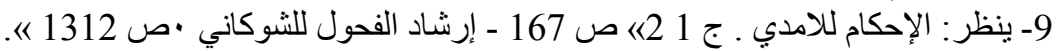

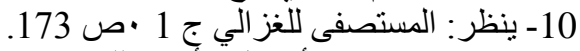

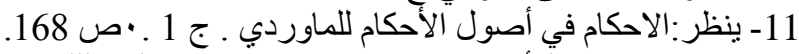

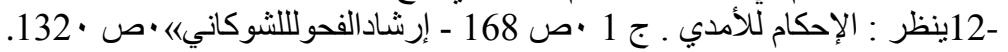

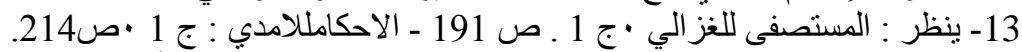

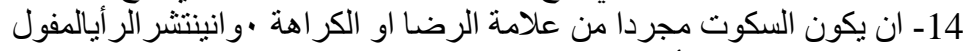

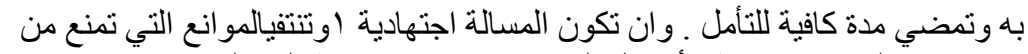

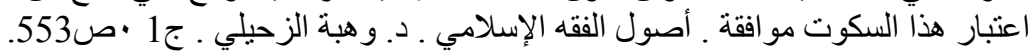

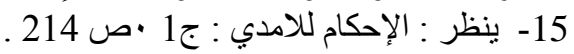




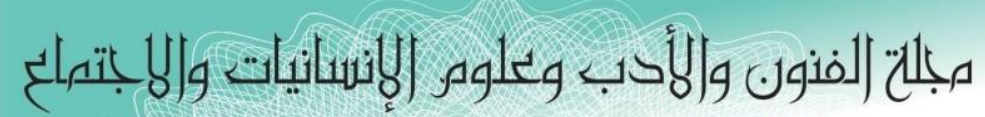

Journal of Arts, Literature, Humanities and Social Sciences

ISSN online: 2414 - 3383

ISSN print: 2616 - 3810

\section{العدد (44) (أكتوبر 2019 \\ Volume (44) October 2019}

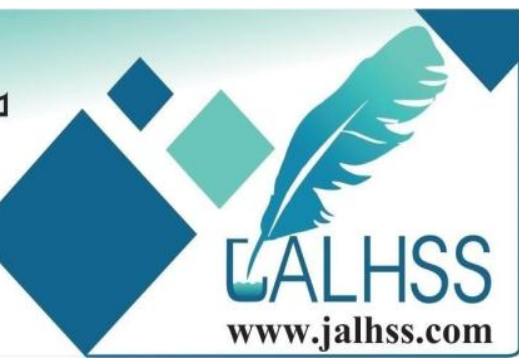

أولاً : إجماع أهل المدينة

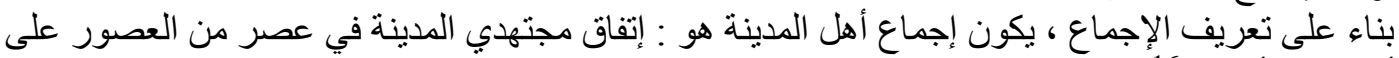

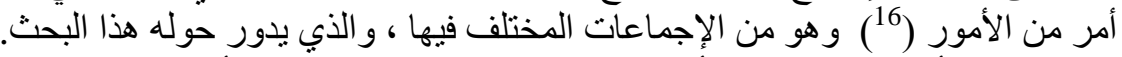

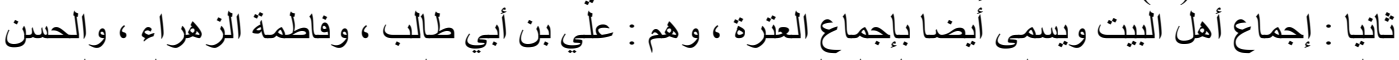

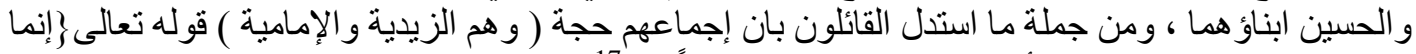

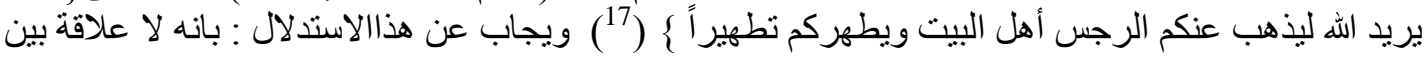

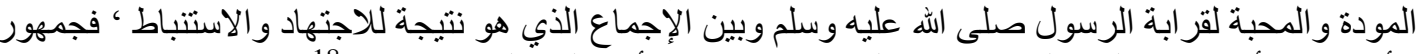

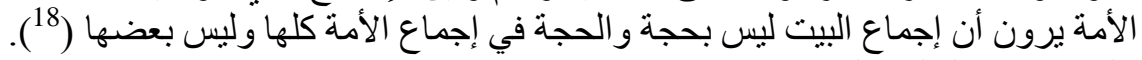

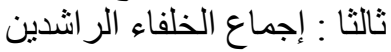

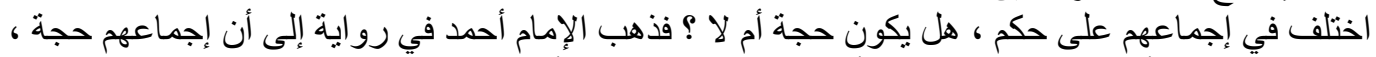

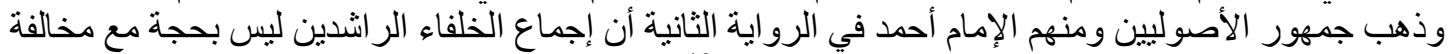

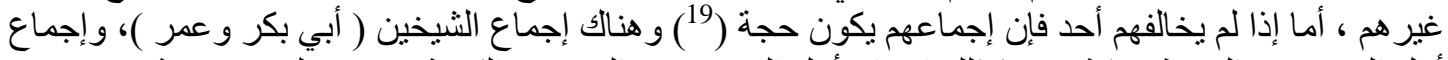

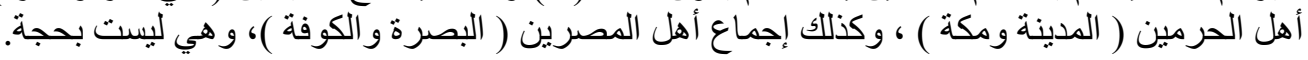

\section{الفصل الثاني

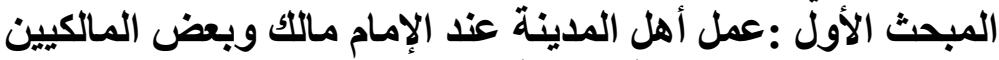

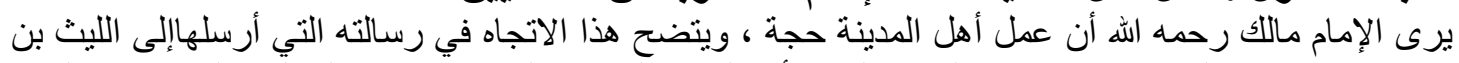

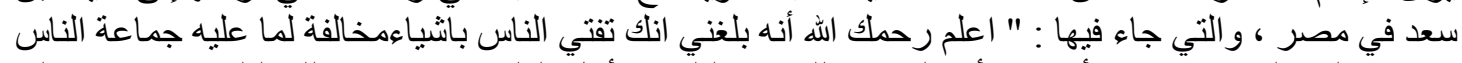

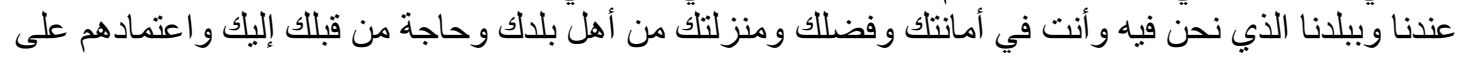

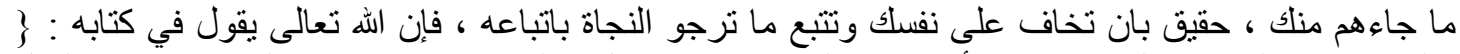

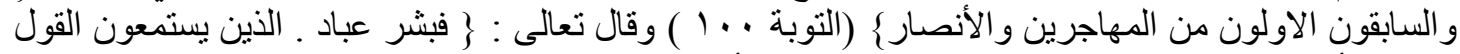

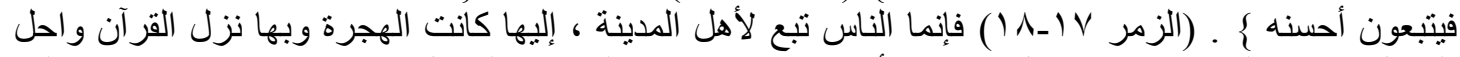

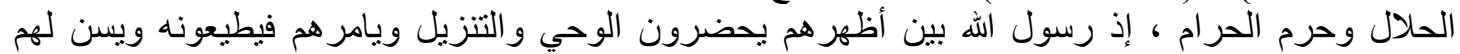

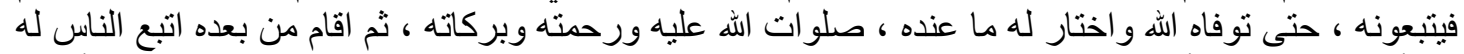

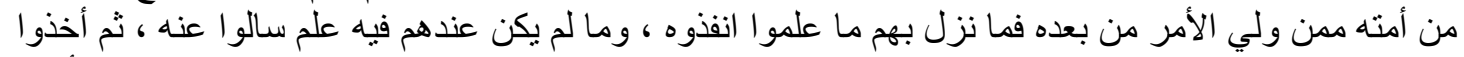

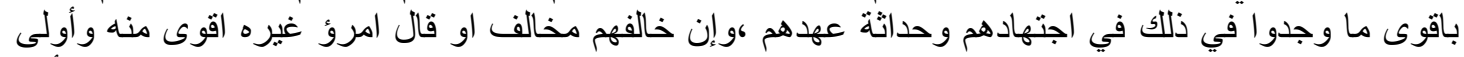

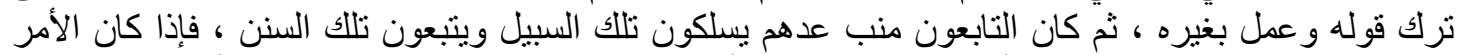

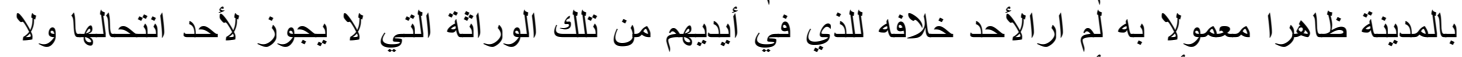

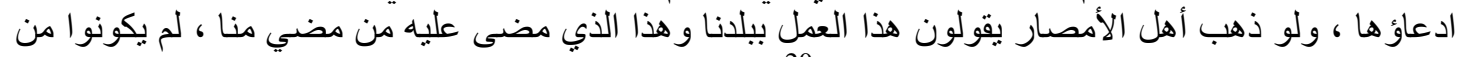

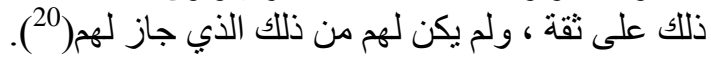

ويعتبر الإمام مالك عمل أهل المدينة أو إجماعهم من مصادر التشريع عنده ومما ينبغي ذكره ، عمل أهل المدام الهينة

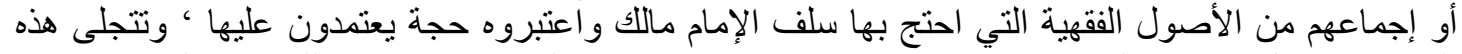

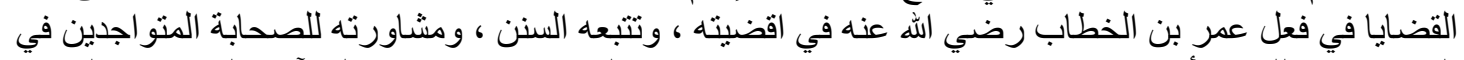

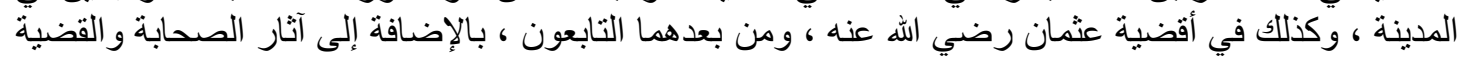

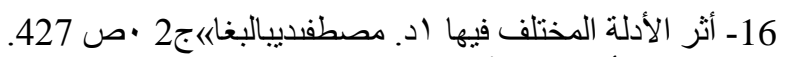
17 - 16 سورة الأحزاب الآية 33.

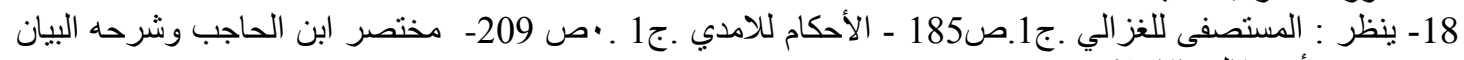

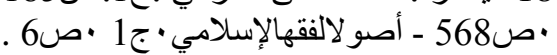

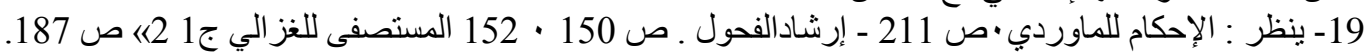

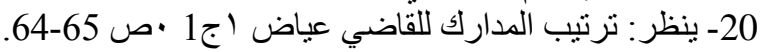




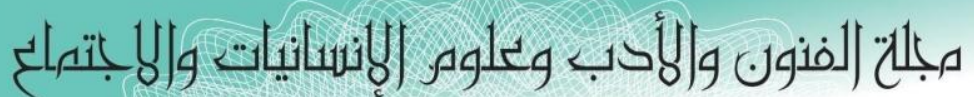

Journal of Arts, Literature, Humanities and Social Sciences

ISSN online: 2414 - 3383

ISSN print: 2616 - 3810

\section{العدد (44) - أكتوبر 2019 \\ Volume (44) October 2019}

LALHSS

WWW.jalhss.com

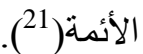

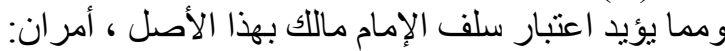

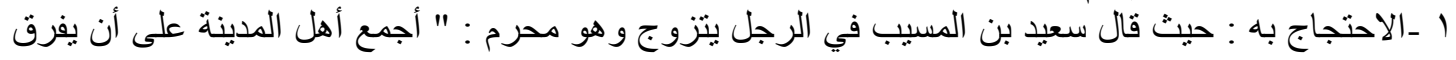

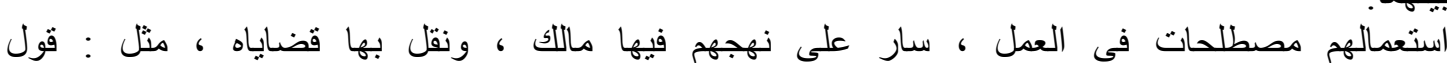

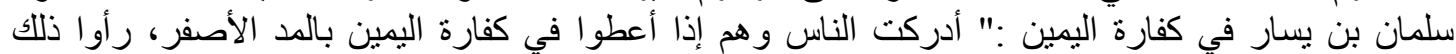

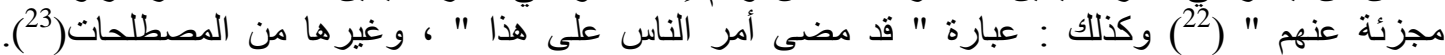

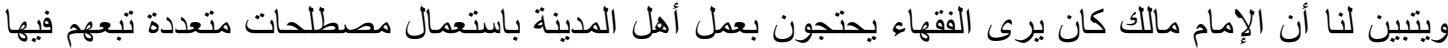

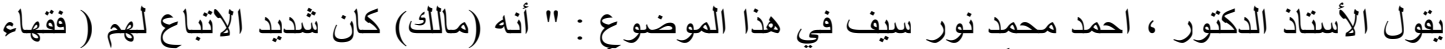

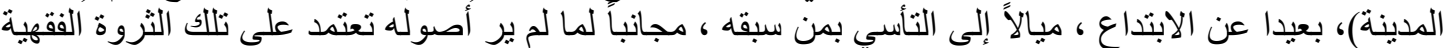

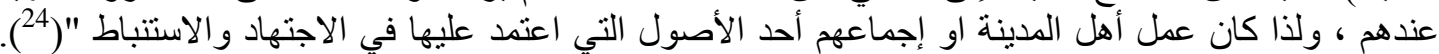
ولقد اختلف في عمل أهل المدينة وكثر الحديث حوله بالنقد و الجدل من المعاصرين للإمام مالك وكذلك الإلك المتاخرين

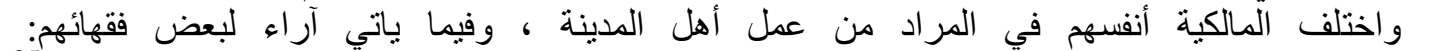

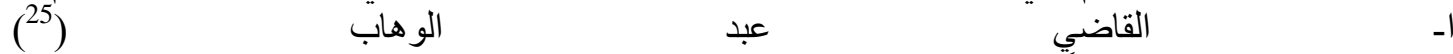

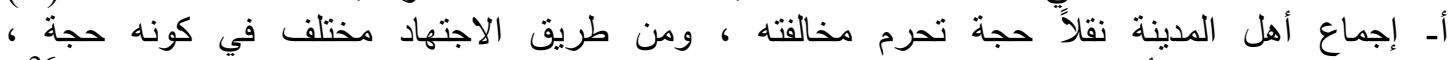

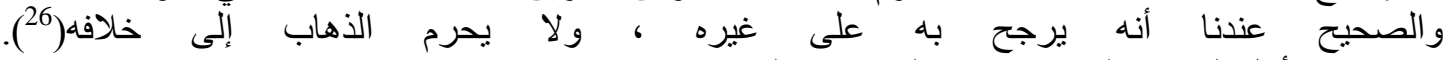

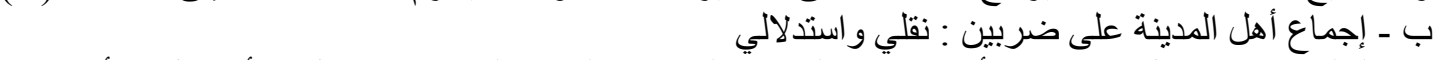
1- النقلي : ومنه نقل شرع مبتدأ من جهة النبي صلى الله عليه وسلم إما من قول الإل ، أو أو فعل ، أو إقرار.

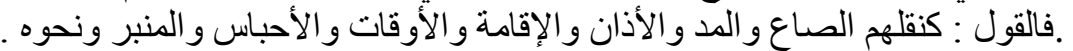

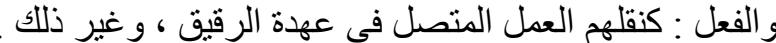

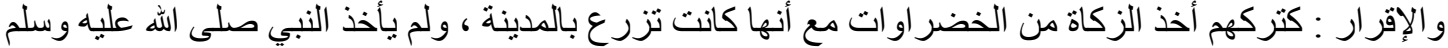

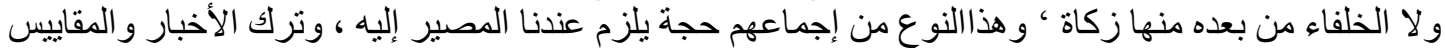

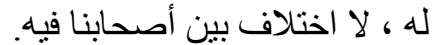

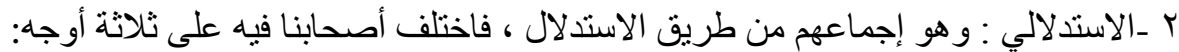

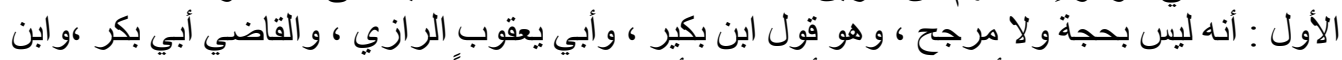

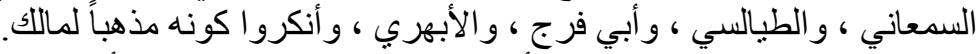

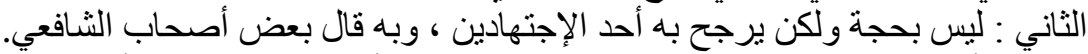

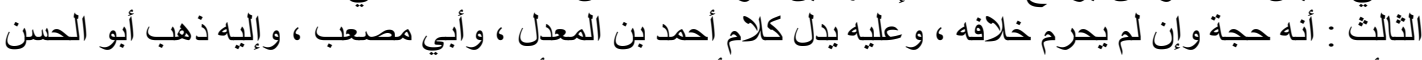

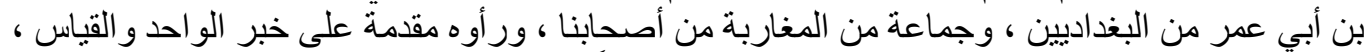
وأطبق المخالفون أنه مذهب ماللك ، و لا يصح عند عند كذا مطلقاً (27).

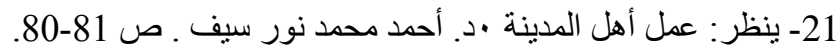

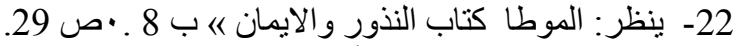

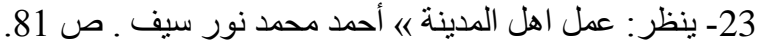

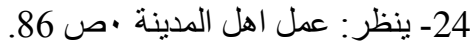

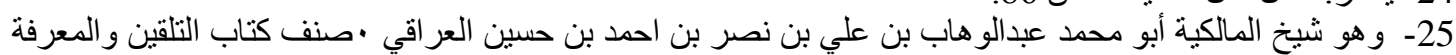
في شرح الرسالة للقيرواني ؛ كان ثقة «) خرج في آخر عمرهالى مصر فمات بها سنة 422 هـ ـ تهذيب سير أعلام النبلاء

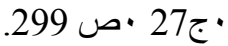
26- ينظر : المعونة على مذهب أهل المدينة للقاضى عبد الوهاب ـ مسالة ملحقة في كتاب المقدمة في الأصول لابن 


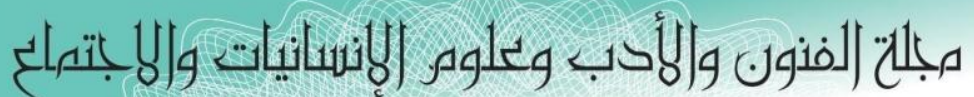

Journal of Arts, Literature, Humanities and Social Sciences

ISSN online: 2414 - 3383

ISSN print: 2616 - 3810

\section{العدد (44) أكتوبر 2019 \\ Volume (44) October 2019}

¿ALHSS

wWw.jalhss.com

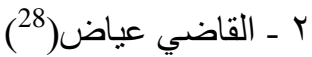

إجماع أهل المدينة على ضربين إضين ، ضرب من طريق النقل و الحكاية الذي تؤثره الكافة عن الكافة و عملت به عملاً

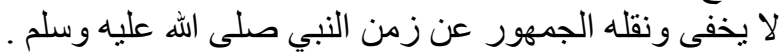

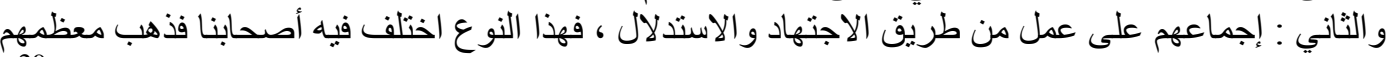

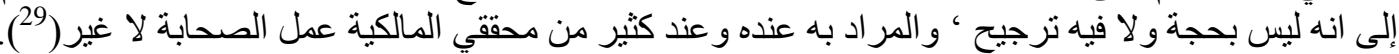

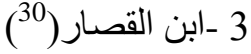

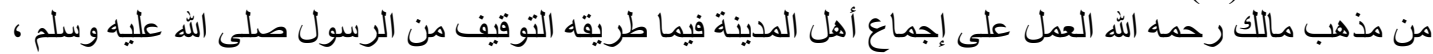

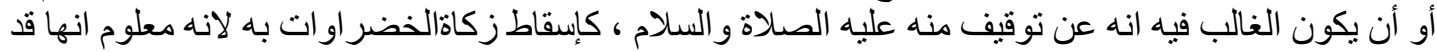

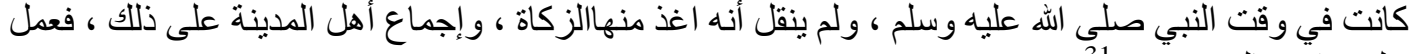
عليه و إن خالفهم غيره(

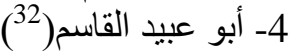

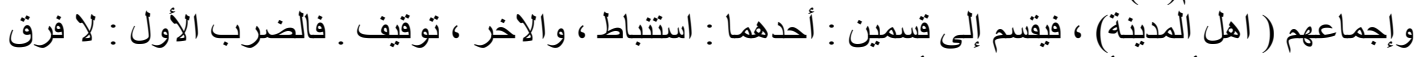

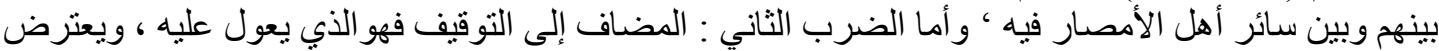

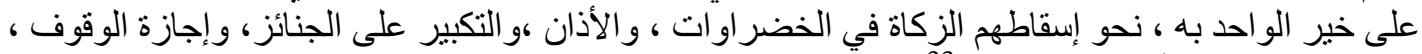

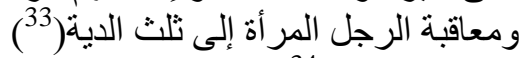

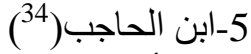
إجماع أهل الددينة من الصحابة والتابعين حجة عند مالك ، و وقيل : محمول على أن روايتهم متقدمةوقيل : على الإنى

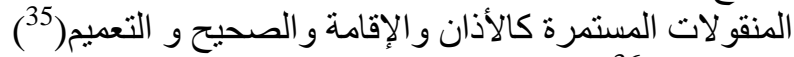

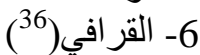

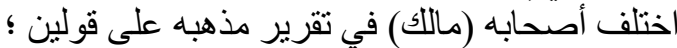

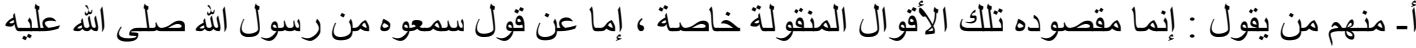

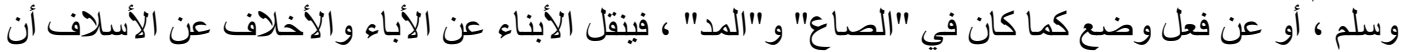

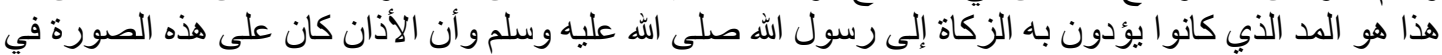

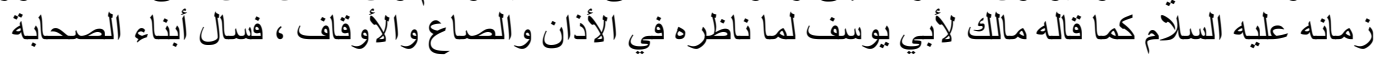

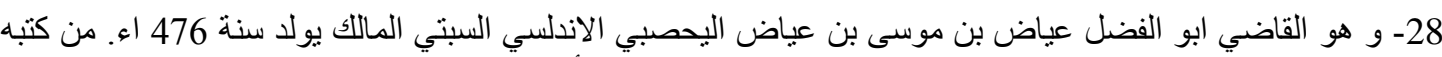

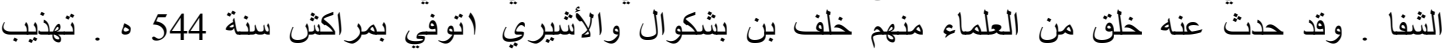

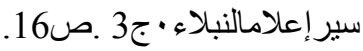

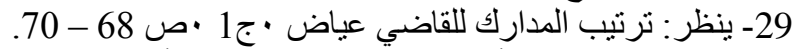

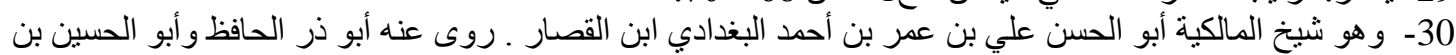

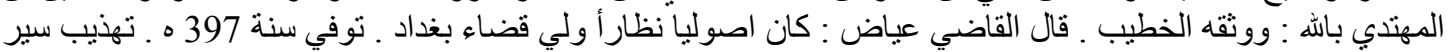

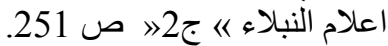

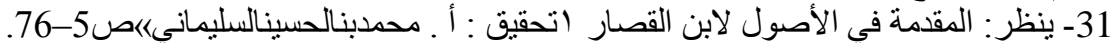

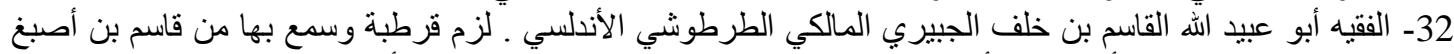

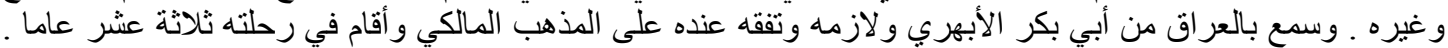

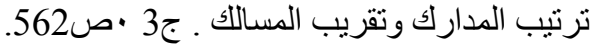
33- ينظر: التوسط بين مالك و التبن القاسم في المسائل التي اختلفا فيها من مسائل المدونة لأبي عبيد القاسم ـ من الملاحق في

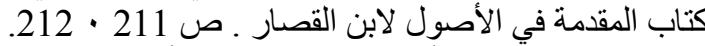

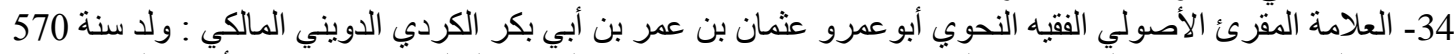

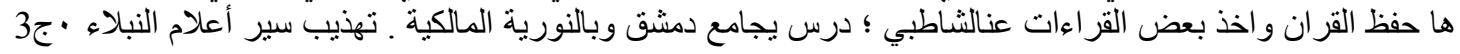

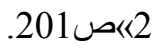

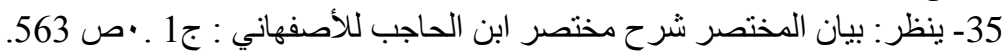

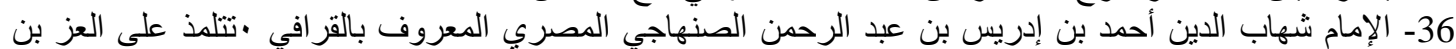

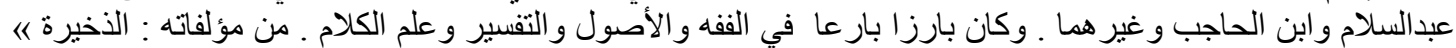

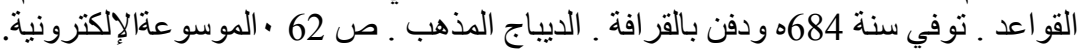




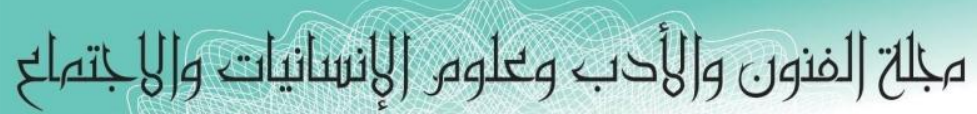

Journal of Arts, Literature, Humanities and Social Sciences

ISSN online: 2414 - 3383

العدد (44) ( أكتوبر 2019 (4)

ISSN print: 2616 - 3810

Volume (44) October 2019

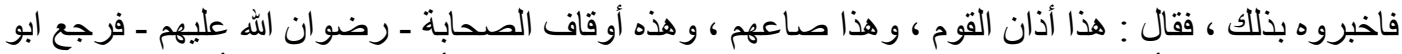

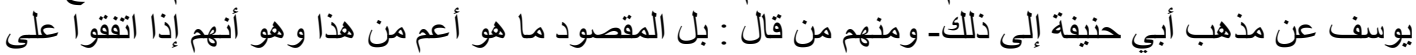

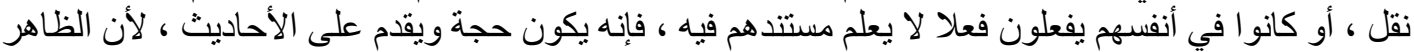

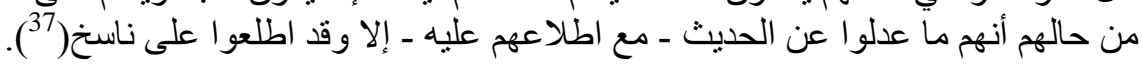

\section{ا المبحث الثاني : رأي بعض الفقهاء والأصوليين في عمل الهل المدينة}

قال في الرسالة ، ولست أقول ولا أحد من أهل العلم : هذا مجتمع عليه إلا لما تلقى عالماً ابدأ إلاقاله للك وحكاه

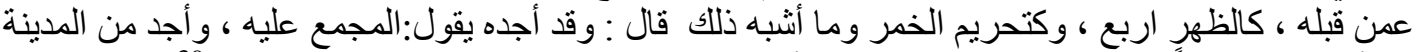

من أهل العلم كثير أ يقولون بخلافه ، و واجد عامة أهل البلدان على خلى خلاف ما يقول المجمع عليه (39).

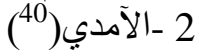

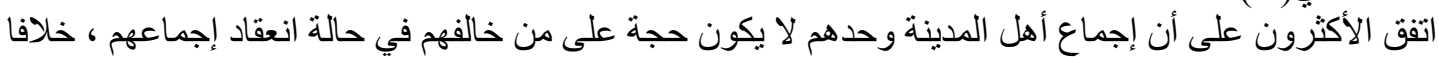

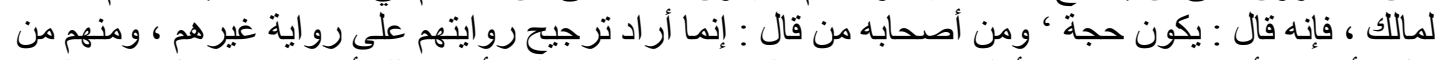

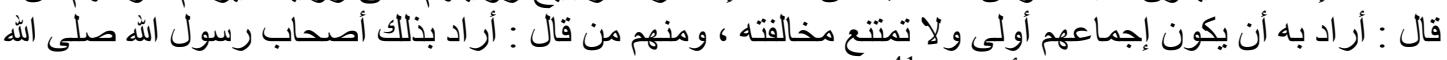

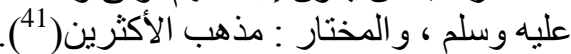

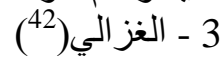

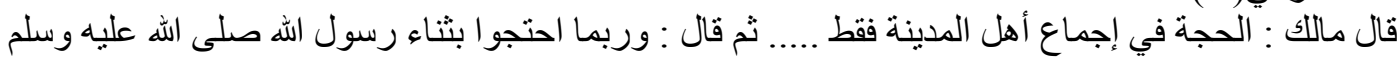
على المدينة و على أهلها ، وذللك يدل على فضيلتهم وكثرة ثو ابهم لسكناهم المدينة ولايدل على تخلي تلصيص الإجماع

به8)

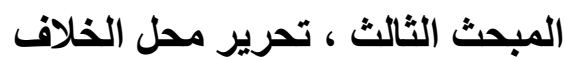

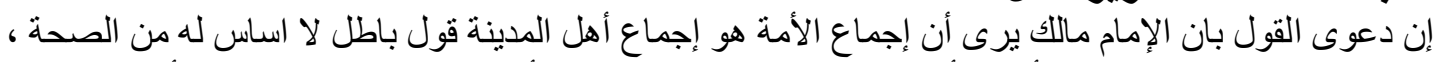

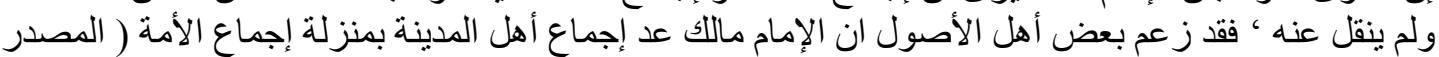

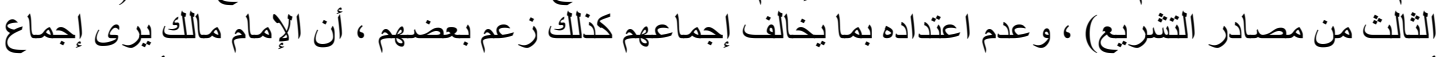

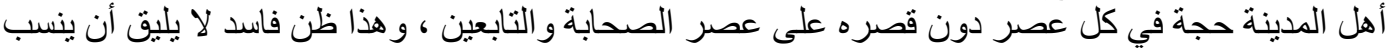
إليه( وبناء على ما ذكر سابقاً من الفهم الخاطئ لمر اد الإمام مالك بعمل أهل المدينة شنع اكثر هم عليه ،يقول القاضي

37- ينظر : عمل أهل المدينة للقرافي ـ مسألة ملحقة في كتاب المقدمة في الأصول لابن القصار ص 223 : 224.

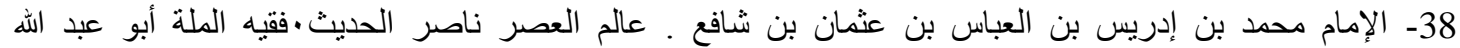

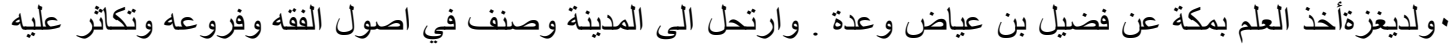

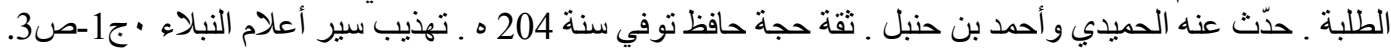

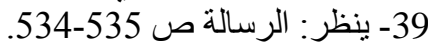

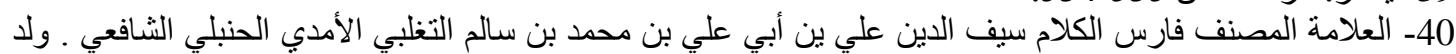

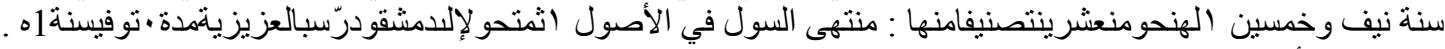

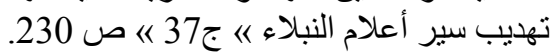

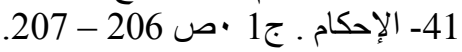

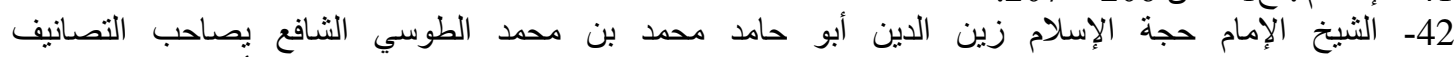

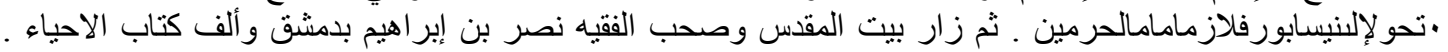

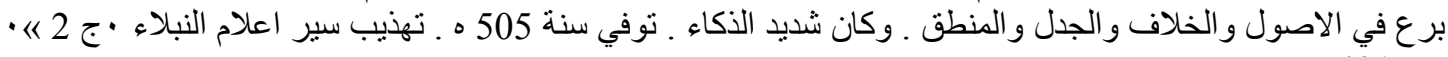

44ـ ينظر: المسائل التي بناها الإمام مالك على عمل أهل المدينة ـ د. محمد المدني بوساق ج1 •ص 68. 


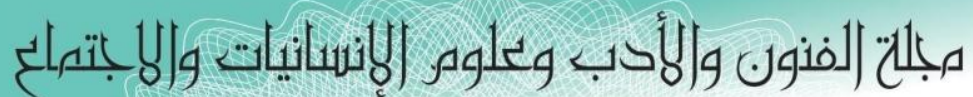

Journal of Arts, Literature, Humanities and Social Sciences

ISSN online: 2414 - 3383

ISSN print: 2616 - 3810

\section{العدد (44) - أكتوبر 2019 \\ Volume (44) October 2019}

¿ALHSS WWW.jalhss.com

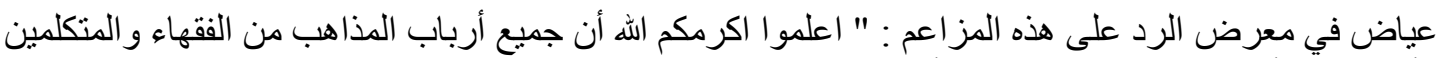

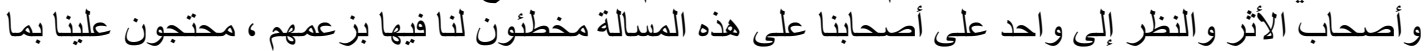

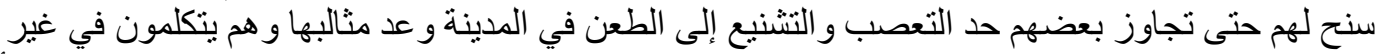

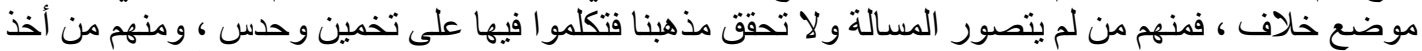

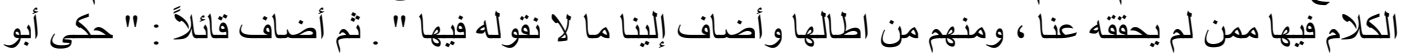

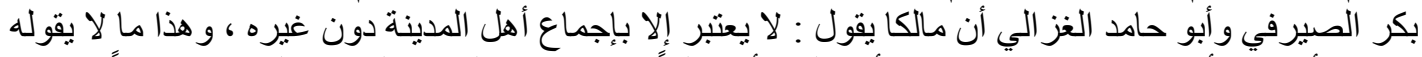

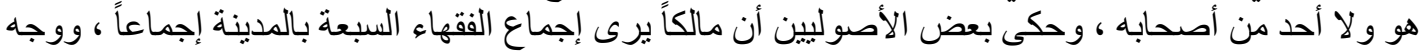

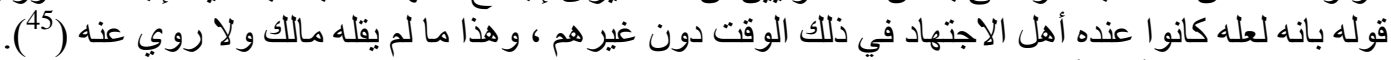

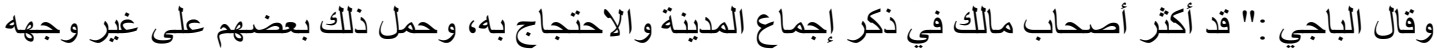

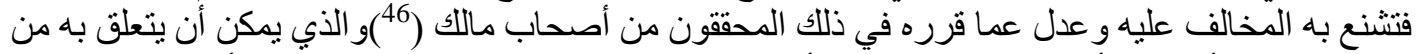
نسب إلى مالك أنه يرى أن الإجماع هو إجماع أهل المال المدينة ( في رسالته إلى الليث بن سعد ) أمران:

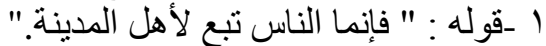

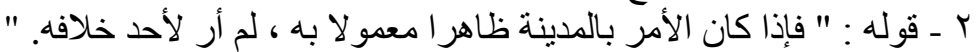

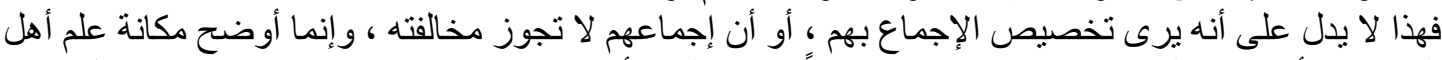

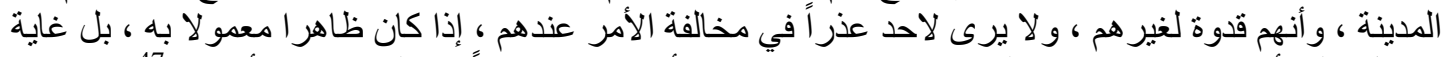

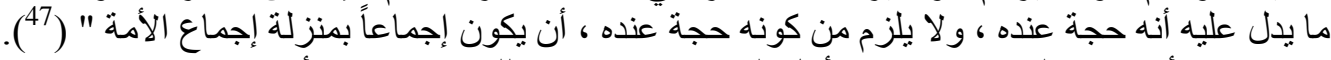
وبهذا ينتفي أن يكون المر اد من إجماع أهل الهن المدينة عند الإمام مالك هو إنماع إنهاع الأمة.

\section{المبحث الرابع : بعض المسائل لأثر الاختلاف في العمل بقول أهل المدينة}

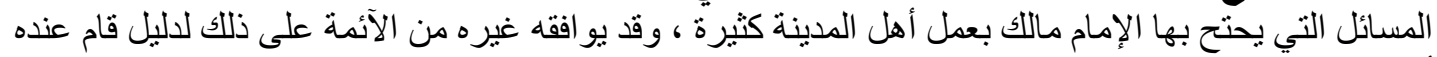

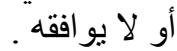
و هذه بعض المسائل المتنوعة التي احتج فيها الإمام ماللك بعمل أهل المدينة:

المسالة الأولى : القر اءة خلف الإمام

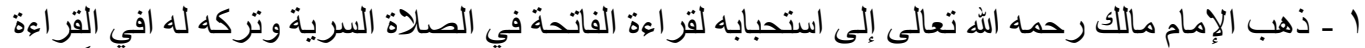

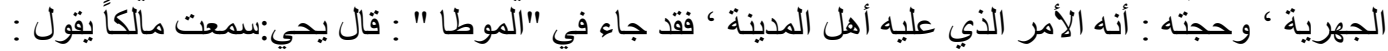

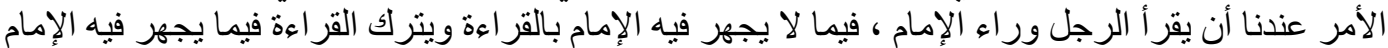

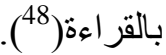
2- "ذهب الإمام الثافعي رحمه الله تعالى إلى وجوب قر اعة الفاع الفاتحة في الصلاة السرية و الجهرية، قال : " فو اجب

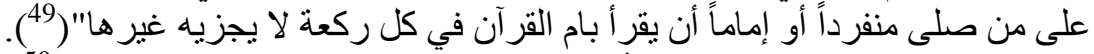

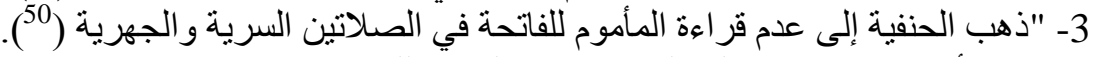

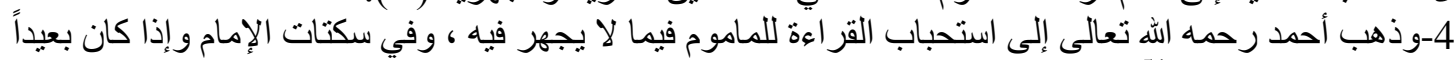
لا يسمع قر اءة الإمام (1).

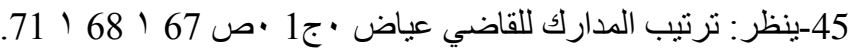

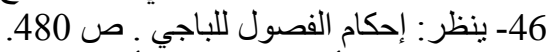

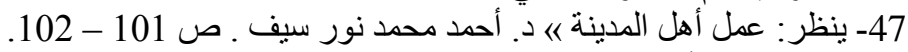

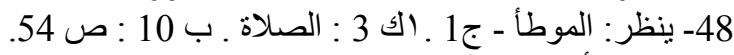

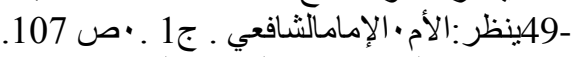

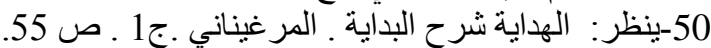

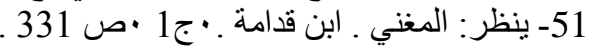




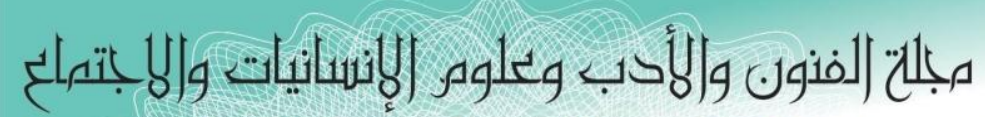

Journal of Arts, Literature, Humanities and Social Sciences

ISSN online: 2414 - 3383

العدد (44) أكتوبر 2019

ISSN print: 2616 - 3810

Volume (44) October 2019

¿ALLHSS

WwW.jalhss.com

المسألة الثانية : توريث ذوي الأرحام

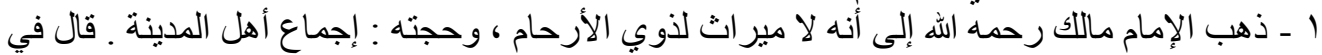

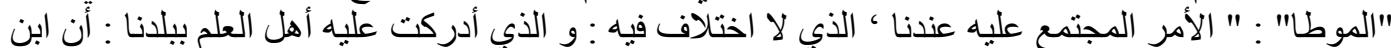

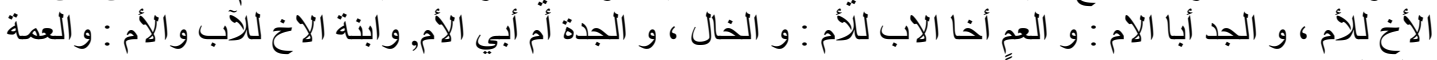

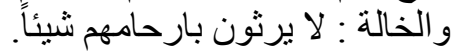

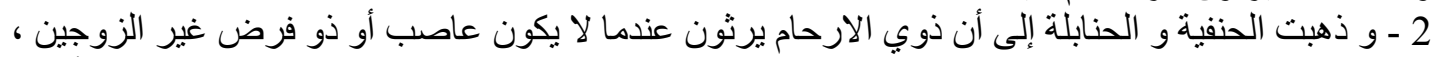

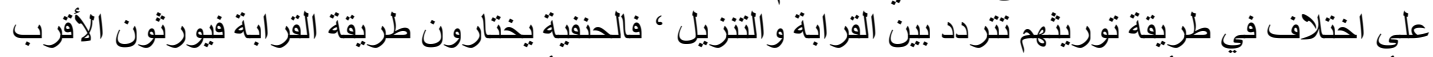

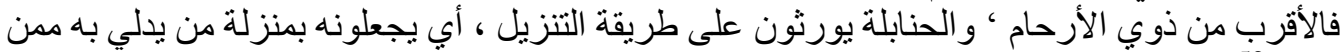

يرث (52).

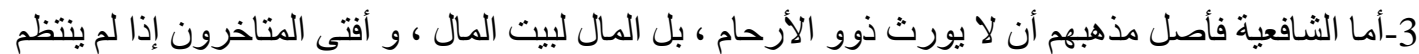

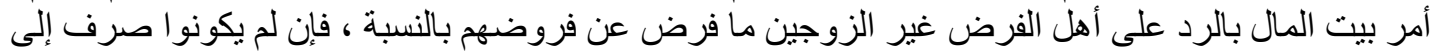

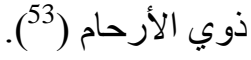

المتالة الثائثة : قتل المسلم بالذمي

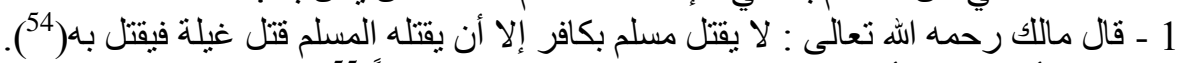

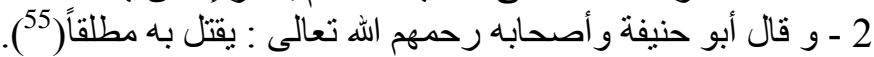

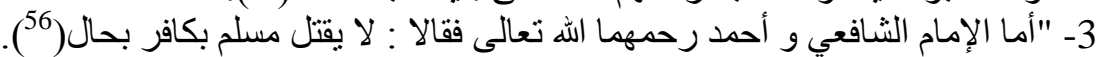

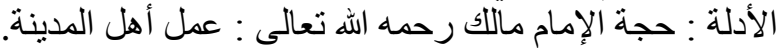

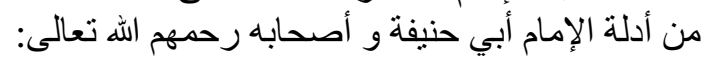

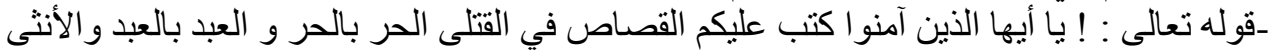

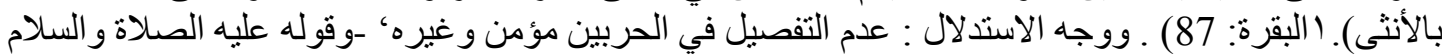

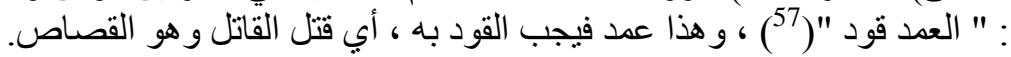

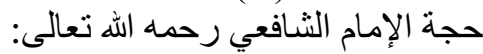

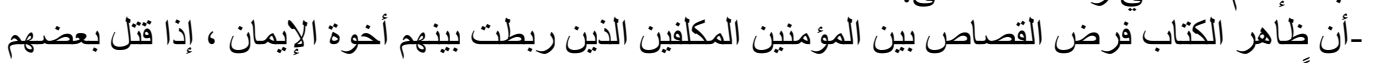

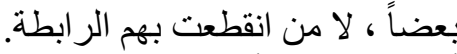

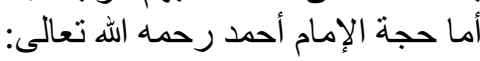
ـقول النبي صلى الله علي الهيه و سلم : " المسلمون تتكافا دماؤ هم ، ويسعى بذمتهم أدناهم ، و لا يقتل مؤمن بكافر (58)" الذمي منقوص بالكفر ، و هو في هذا كالمستأمن ، و مو افقة أبي حنيفة الجماعة على أن المسلم لايقاد بالمستامن

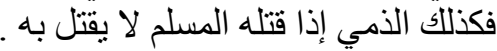
المسألة الر ابعة : المقدار المحرم في الرضاع الرئاع اتفق العلماء على أن الرضاع ئثبت حرمة النكاح كما يثبتها النسب ، و إنما اختلفو ا في مسائل

52- ينظر: الموطأ ج2 ا 27 «الفرائض ـ ب 12 ـ.ص 56،و المغني . ابن قدامة . ج6 :•ص 207-206 -

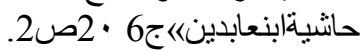

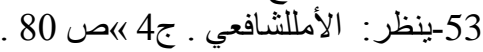

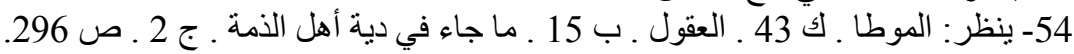

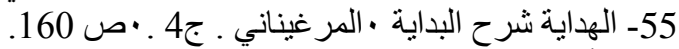

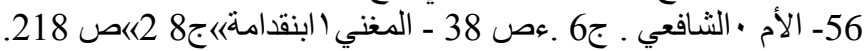

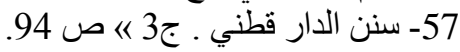

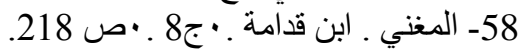




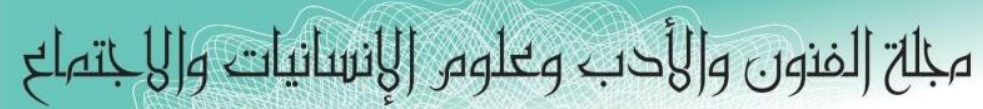

Journal of Arts, Literature, Humanities and Social Sciences

ISSN online: 2414 - 3383

ISSN print: 2616 - 3810

\section{العدد (44) أكتوبر 2019 \\ Volume (44) October 2019}

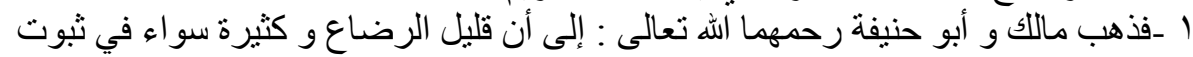 \\ متعلقة بالرضاع ، منها : المقدار الذي بثبت بـه التحريم :} قال الإمام مالك في الموطأ : الرضاعة قليلها و كثيرها إذا كان في الحولين تحرم (59).

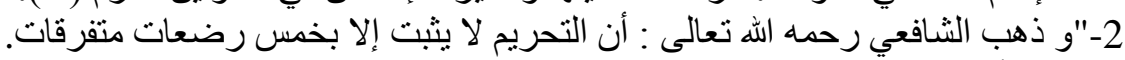

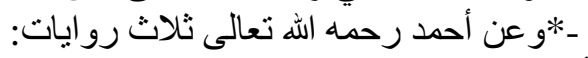

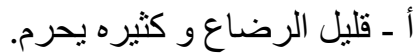

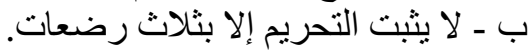

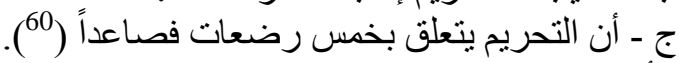
الأدلة:

حجة الإمام مالك : عمل أهل الهام المدينة.

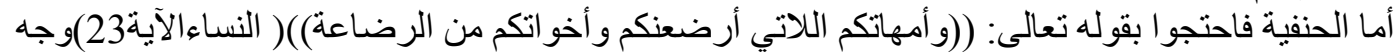

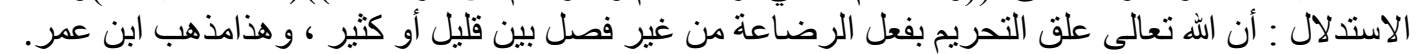

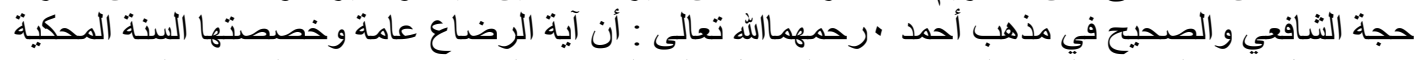

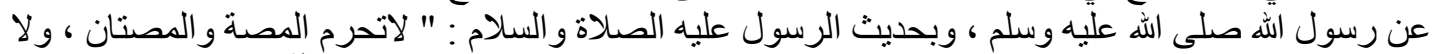

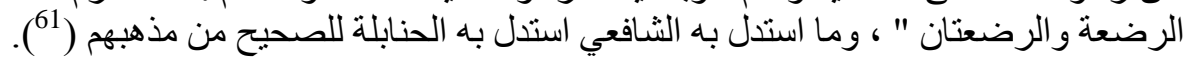

خاتمة البحث ونتائجه

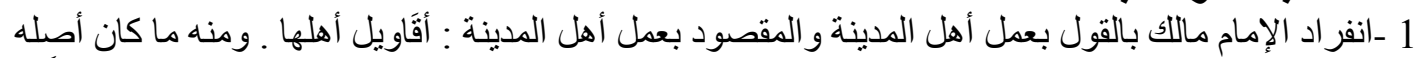

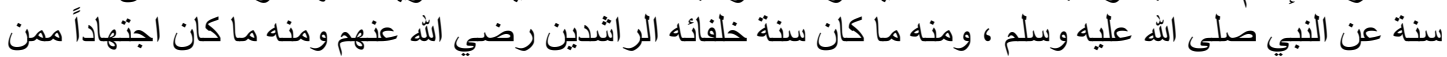
بعدهم من الصحابة و التابعين.

2- بطلان الدعوى القائلة بان الإمام مالك يرى أن إجماع الأمة هو إجماع أهل المدينة وأن إجماع أهل المدينة

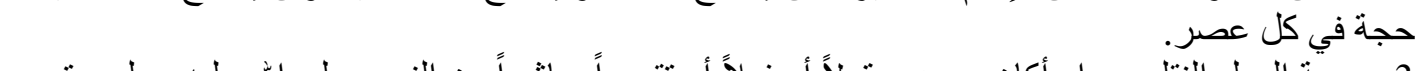
3- حجية العمل النقلي سواء أكان مصدره قو لاً أو فعلاً أو تقرير اً مبانر اً من النبي صلى اله عليه وسلم و تحريم مخالفته. 4 - أن الخلاف في إجماع أهل المدينة فيما طريقه الاجتهاد و الاستدلال و الاستنباط. 5 - أن العمل القديم لأهل المدينة الملة حجة. 6 - عدم حجية العمل المتأخر بالمدينة.

7 ـأن عمل أهل المدينة الذي و افقه دليل وخالفه آخر ، اختلف فيه : فمنهم من برجح بعمل أهل المدينة ، ومنهم لا

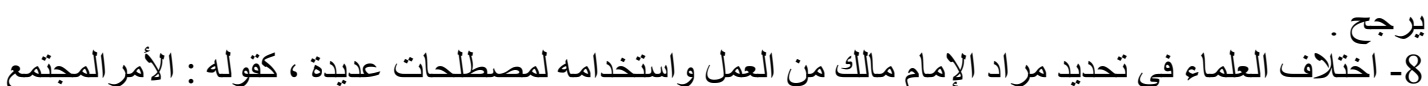

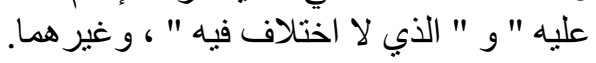

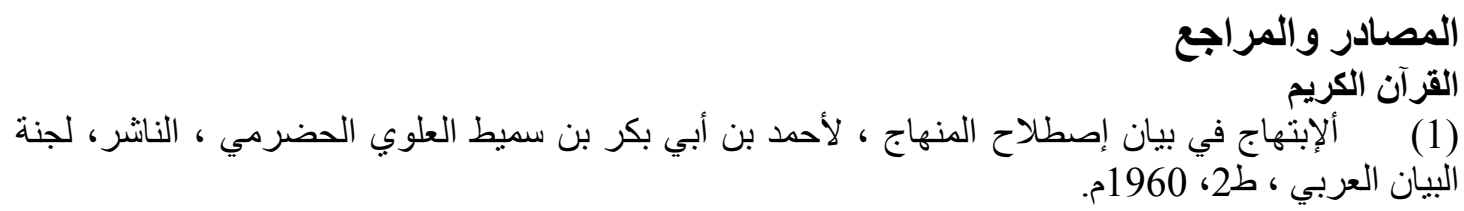

59- ينظر: الموطأ- ك 30 الرضاع ـ ب رضاعة الصغير . ج2 《 ص 113 ـ الهداية شرح البداية للمرغيئاني . ج1

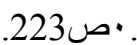

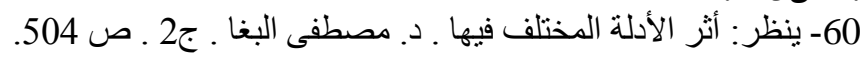

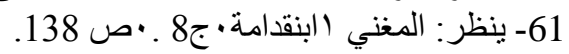




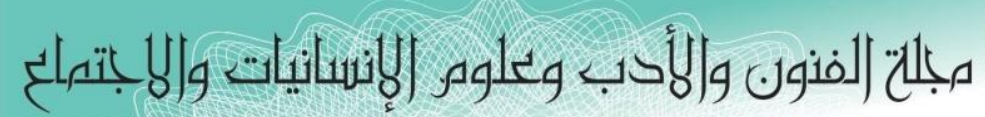

Journal of Arts, Literature, Humanities and Social Sciences

ISSN online: 2414 - 3383

ISSN print: 2616 - 3810

\section{العدد (44) أكتوبر 2019 \\ Volume (44) October 2019}

(2) إتحاف السادة المتقين بشرح إحياء علوم الدين، للعلامة السيد محمد بن محمد الحسيني الزبيدي الثهير

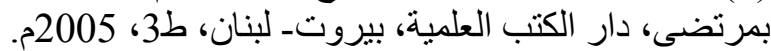

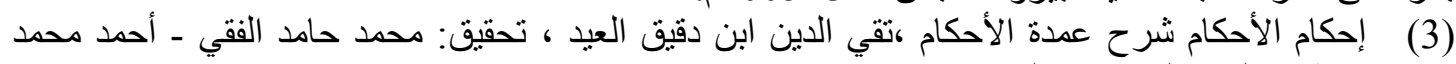

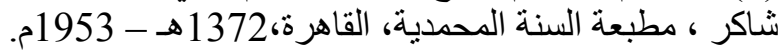

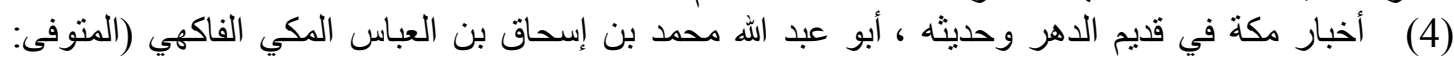

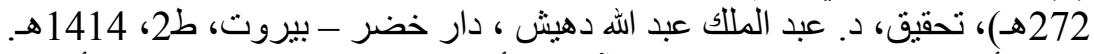

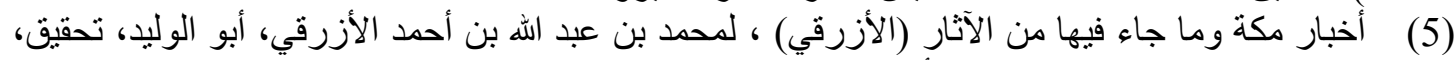

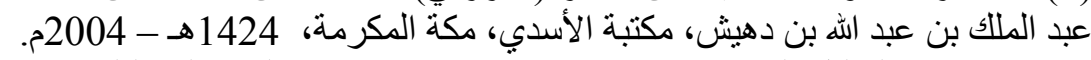

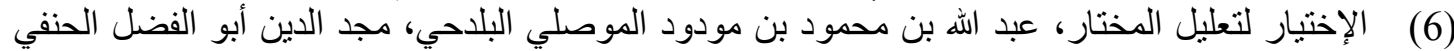

(المنوفى: 683هـ)، عليها نعليقات :الثيخ محمود أبو دقيقة (من علماء الهئ الحنفية ومدرس بكلية أصول الدين سابقا)،

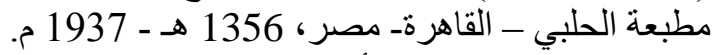

(7) إرشاد السالك إلى أفعال المناسك ، إبراهيم الهيم بن فرحون المدني المالكي ، تحقيق محمد أبو الأجفان ،

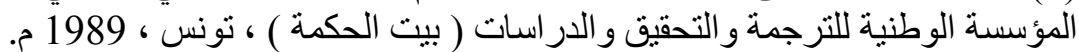

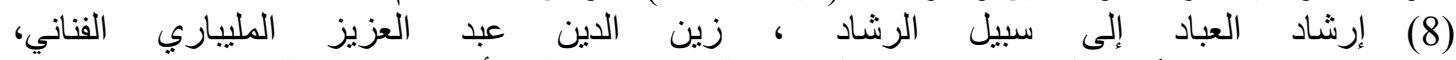

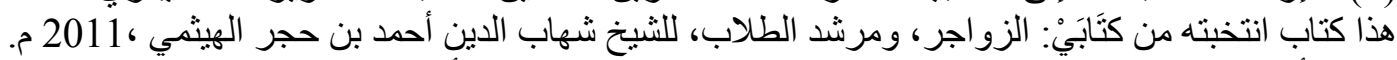

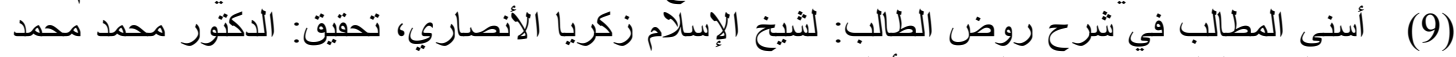

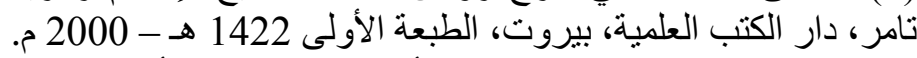

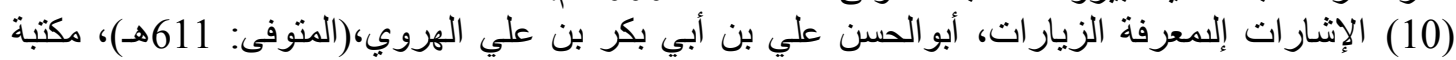

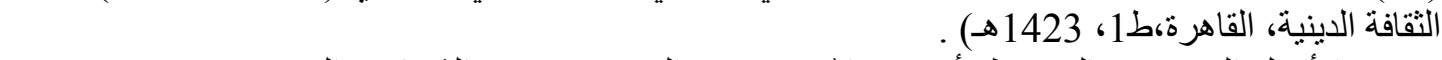

(11) الأصل المعروف بالمبسوط، أبو عبد الله محمد بن الحسن بن فرقد الثنيباني (المنوفى: 189هـ)، تحقيق،

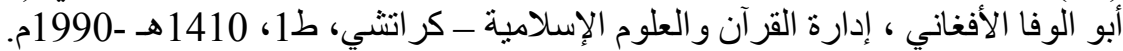

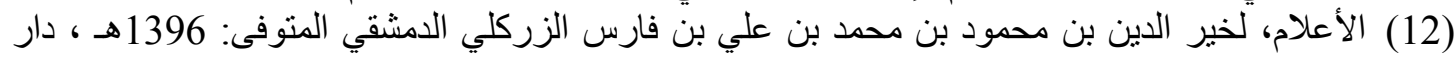

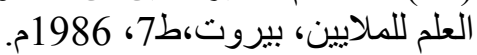

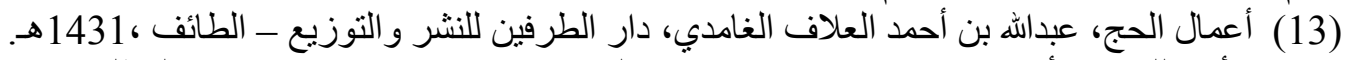

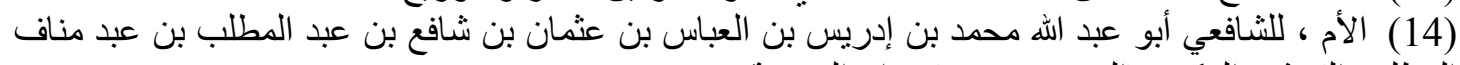

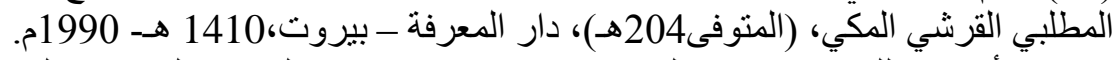

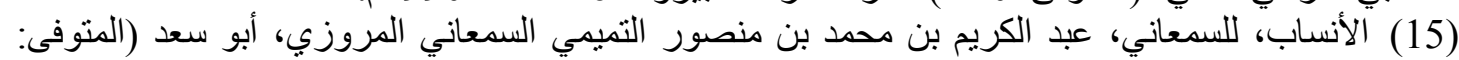
562هـ)، تحقيق، عبد الرحمن بن يحيى المعلمي اليماني ، مجلس دائرة المعارف العثمانية، حيدر آباد،ط1، التئ،

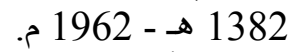

(16) الأنوار القدسية في الأحو ال الثخصية، عبدالكريم محمد المدرس، مطبعة الجاحظ - بغداد،1، 1410

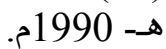

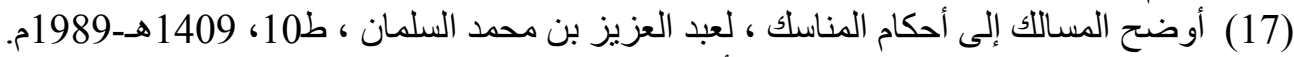

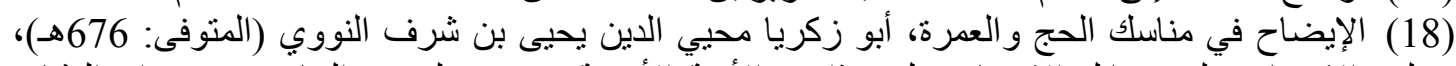

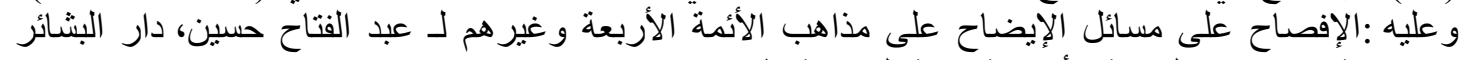

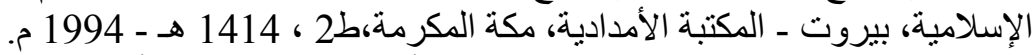

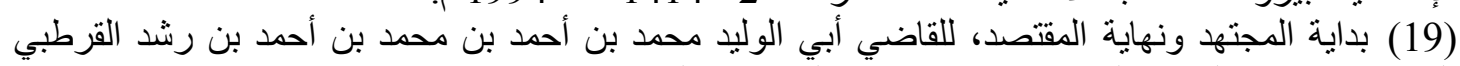

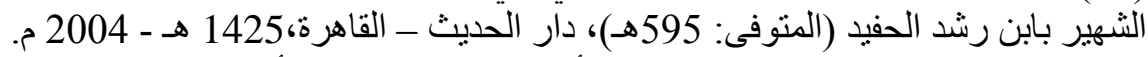

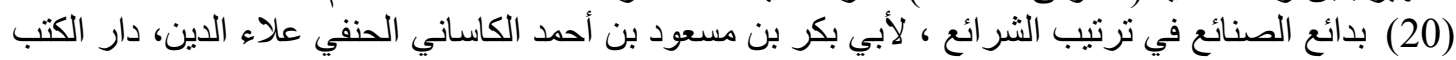

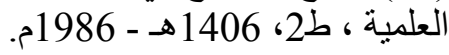
(21) البدر الطالع بمحاسن من بعد القرن السابع، للقاضي العلامة محمد بن علي الثوكاني (ت: 1250 هـ)،

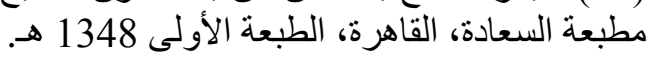
(22) البناية في شرح الهداية، لأبي محمد محمود بن علي الألي العيني (ت: 855 هـ)، دار الفكر، بيروت، الطبعة

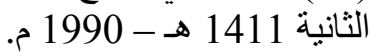




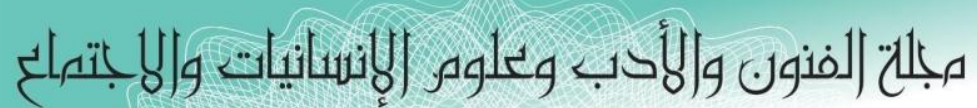

Journal of Arts, Literature, Humanities and Social Sciences

ISSN online: 2414 - 3383

ISSN print: 2616 - 3810

\section{العدد (44) أكتوبر 2019 \\ Volume (44) October 2019}

LALHSS

nmus.jallsssom

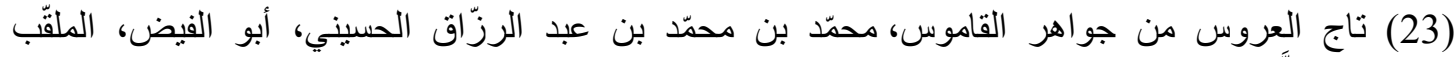

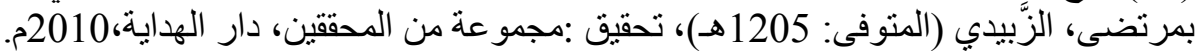

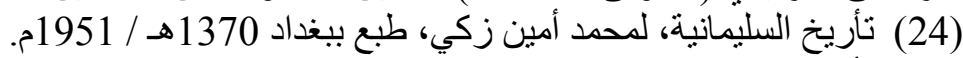

(25) نأريخ الفقه الإسلامي ـ د ـ ناصر بن عقيل الطريفي ، مكتبة التوبة ، الرياض ، ط ط 2 ، 1418 هـ / 1997 ـ 1957

(26) نأريخ الفقه الإسلامي ،لمحمد علي السايس ، دار الكتب العلمية ،بيروت ـ لبنان،2011م 2010م.

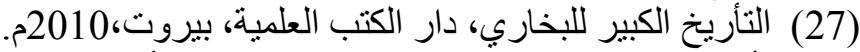

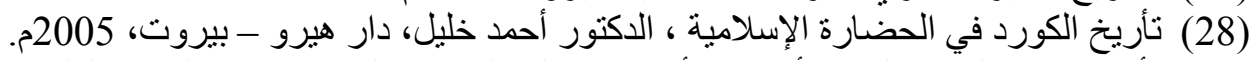

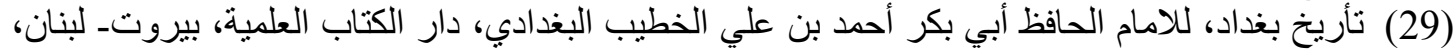

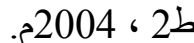

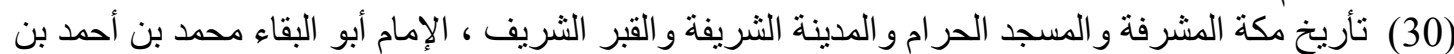

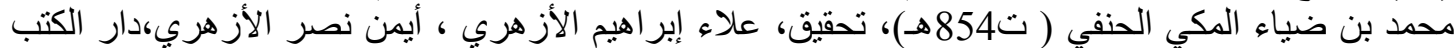

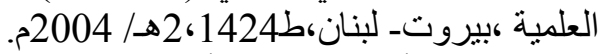

(31) تحرير ألفاظ التنبيه ، أبو زكريا محيب الدين يحيى بن شرف الفئ النووي (المتوفى: 676هـ)، تحقيق :عبد

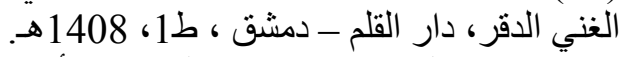
(32) تحفة المحتاج في شرح المنهاج، لأحمد بن محمد بن علي بن حجر الهيتمي ، المكتبة التجارية الكبرى

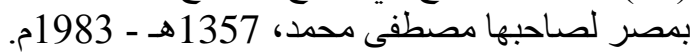
(33) التحقيق، لأبي زكريا يحيى بن شرف النيف النووي الثافعي، تحقيق ،عادل عبد الموجودـ- الثيخ علي معوض،

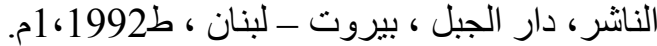

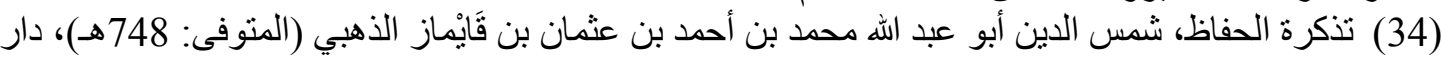

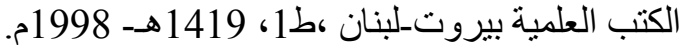
(35) ترنيب المدارك وتقريب المسالك لمعرفة أعلام مذهب ماللك، أبو الفضل القاضي عياض بن موسى المئ

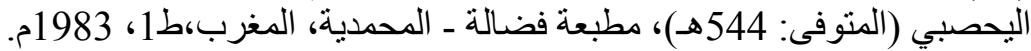

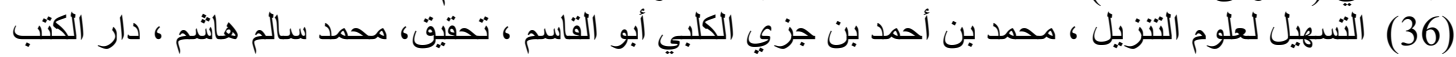

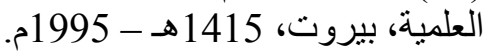
(37) التعريفات، علي بن محمد بن علي الزين الثريف الجرجاني المتوفي(816هـ) دار الكتب العلمية - بيروت

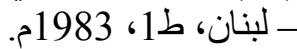
(38) تفسير القرآن العظيم (تفسير ابن كثير) ،إسماعيل بن عمر بن كثير القرشي الدمشقي أبو الفداء عماد الدين

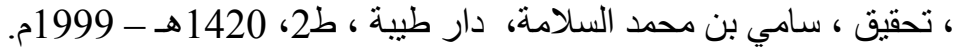
(39) تقريب التهذيب ، أبو الفضل أحمد بن علي بن بن محمد بن بن أحمد بن حجر العسقلاني (المتوفى: 852هـ)،

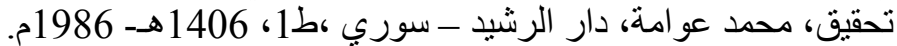

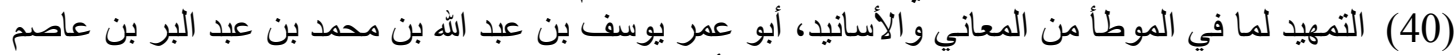

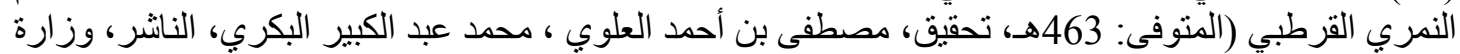

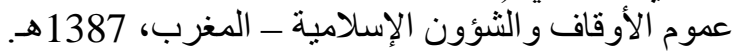

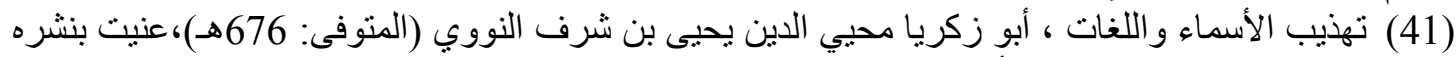
وتصحيحه و التعليق عليه ومقابلة أصوله: شركة العلماء بمساعدة إدارة الطباعة المنيرية، دار الكتب العلمية،

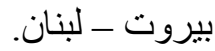
(42) نهذيب التهذيب، أبو الفضل أحمد بن علي بن محمد بن أحمد بن حجر العسقلاني (المتوفى: 852هـ،

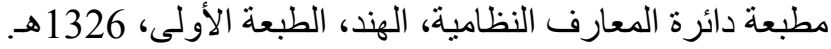
(43) تهذيب الكمال في أسماء الرجال، لأبي الحجاج يوسف الألى المزى، تحقيق: د. بشار عواد، مؤسسة الرسالة،

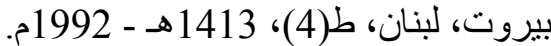
(44) تهذيب اللغة، للأزهري، محمد بن أحمد، تحقيق: عبد السلام هارون، مكتبة الخانجي، القاهرة، ط(1)،

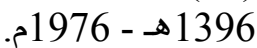




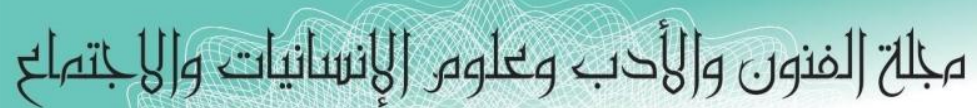

Journal of Arts, Literature, Humanities and Social Sciences

ISSN online: 2414 - 3383

ISSN print: 2616 - 3810

\section{العدد (44) أكتوبر 2019 \\ Volume (44) October 2019}

LALHSS

mun.jalhsscom

(45) الجامع الصحيح (اسنن الترمذي)، لأبى عيسى محمد بن عيسى بن سورة، تحقيق: د. بشار عو اد معروف،

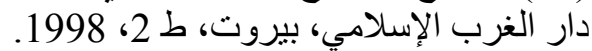

(46) جمع الجوامع ، لقاضي القضاة تاج الدين عبد الوهاب بن علي السبكي ، دار الكتب العلمية، بيروت_لبنان،

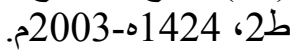

(47) جهود الثيخ عبدالكريم المدرس الفقهية ، للدكتور عبداله سعيد ويسي الكرتكي، مطبعة ماردين-أربيل،

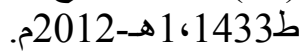

(48) جواهر الفتاوى خير الزاد في الإرشاد ، عبدالكريم محمد المدرس ، مطبعة دار البصري- بغداد، ط1، 1389 هـ - 1969 هـ الهندي

(49) حاثية البجيرمي على شرح المنهج (التجريد لنفع العبيد) ، سليمان بن محمد البجيرمي ، مطبعة دار الكتب

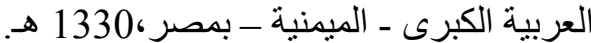
(50) حاثية الترمسي-المسمات المنهل العميم بحاثية المنهج القويم- على شرح العلى العلامة ابن حجر مقدمة

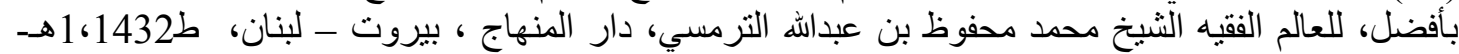

(51) حاثشية الجمل على المنهج، لسليمان بن عمر بن منصور العجيلي المصري، الثهير بـرالجملی)، دار

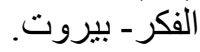
(52) حاثشية الدسوقي على الثرح الكبير، لمحد عرفه الدسوقي، تحقيق: محد عليش، دار إحياء الكتب

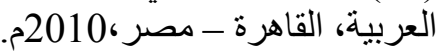
(53) حاثنية الروض المربع شرح زاد المستقنع ، عبد الرحمن بن محمد بن قاسم العاصمي النجدي الحنبلي ،

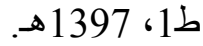

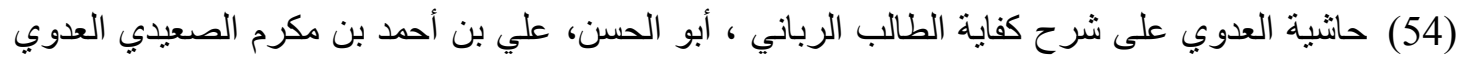

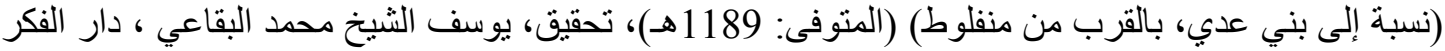

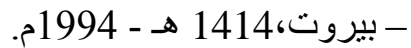
(55) حانشية العلامة ابن حجر الهيتمي على شرح الإيضساح في مناسك الحج للإمام النووي ، للعلامة أحمد بن

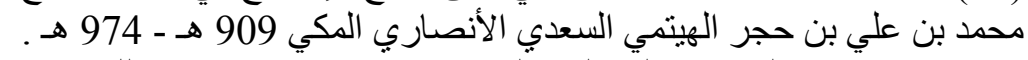

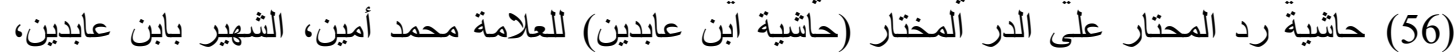

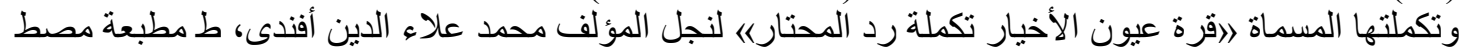
في البابى الحلبى ـ الطبعة الثنانية. (57) حاثنيت القليوبي و عميرة على شرح الفيرة المحلى على منهاج الطالبين، أحمد سلامة القليوبي وأحمد البرلسي

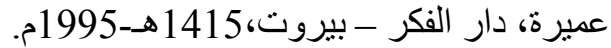

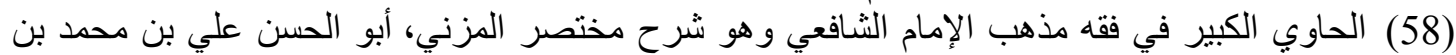

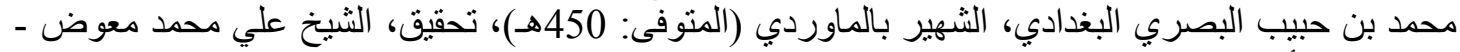

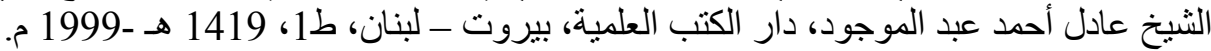

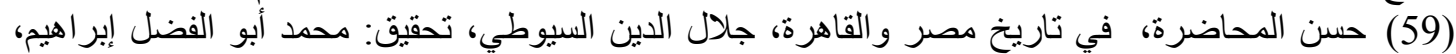

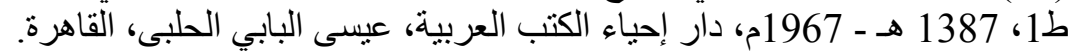

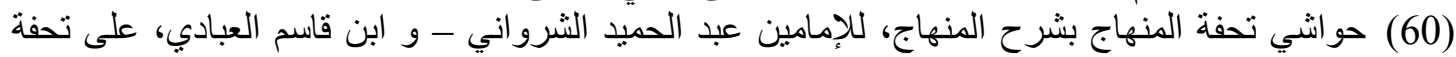

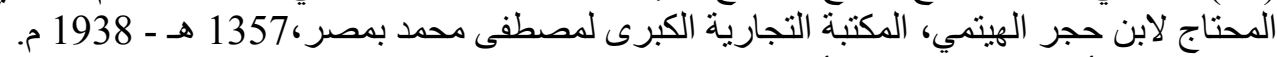

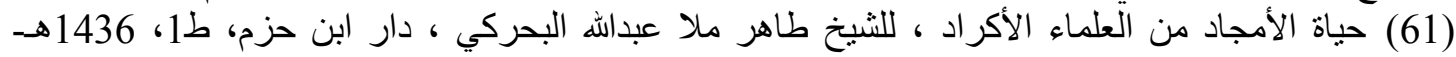
2015م، بيروت_البنان.

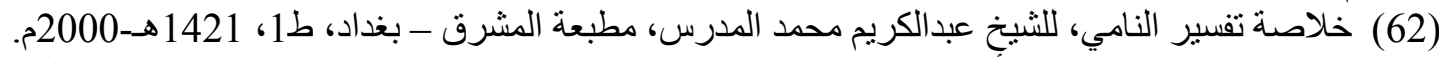

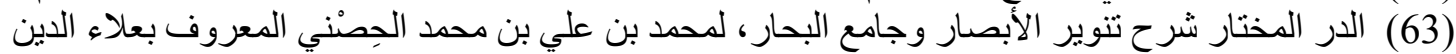
الحصكفي الحنفي (المتوفى: 1088ه)، تحقيق :عبد المنعم خليل إبراهيخ، دارئ دار الكتب العلمية، ط1، 1423 هــ 


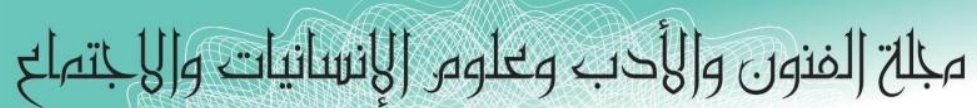

Journal of Arts, Literature, Humanities and Social Sciences

ISSN online: 2414 - 3383

العدد (44) أكتوبر 2019

ISSN print: 2616 - 3810

Volume (44) October 2019

(64) الدرر الكامنة في أعيان المائة الثامنة، لابن حجر العسقلاني دائرة المعارف العثمانية، حيدر آباد، الهند،

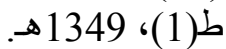

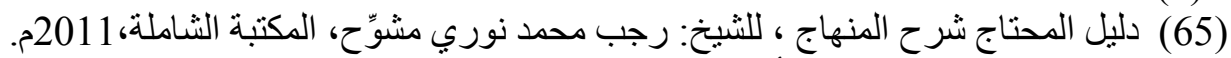

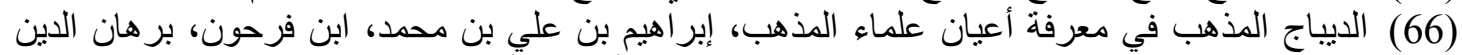

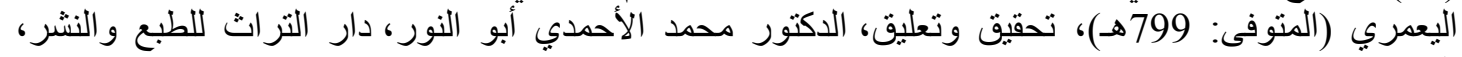

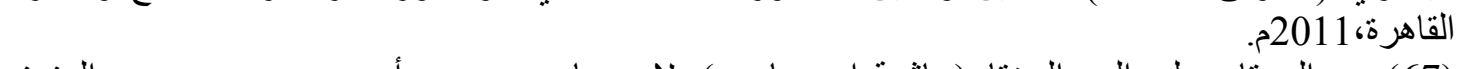

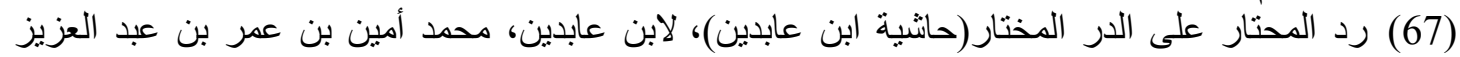

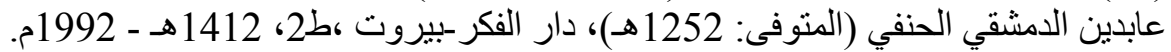

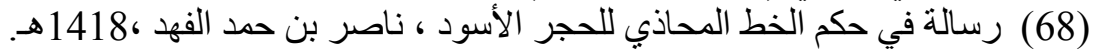

(69) رسائل الرحمة في المنطق و الحكمة ، للشيخ عبدالكريم محمد المدرس ، الدارئ الدار العربيةـ القاهرة، ط1،

(70) رسائل العرفان في الصرف والنحو والوضع والبيان، للشيخ عبدالكريم محمد المدرس، الدار العربية ـ

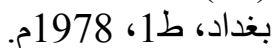

(71) روزكاري زيانم ( أيام حياتي) ، للثيخ عبدالكريم محمد المدرس، مطبعة كوردستان، سنهـ إيران،

(72) الرّوض المربع بشرح زاد المستقنع - مختصر المقنع ـ للإمام منصور بن يونس البهوتي، ط دار الكتب

العلمية، بيروت، الطبعة الثنامنة.

(73) روضة الطالبين و عمدة المفتين، لأبى زكريا يحيى بن شرف النئة النووي ، تحقيق عادل عبد الموجود و علي

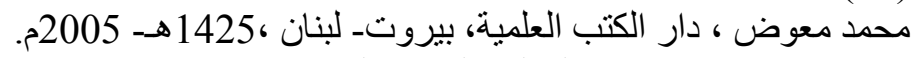

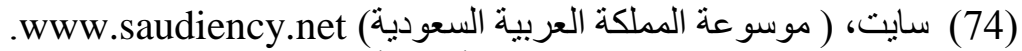

(75) سبل السلام شرح بلوغ الأبر المر ام من أدلة الأحكام ، لمحمد بن إسماعيل الأمير الصنعاني ، تحقيق، محمد

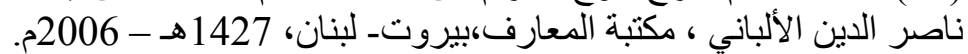

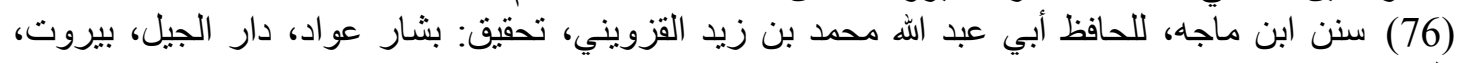

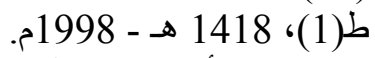

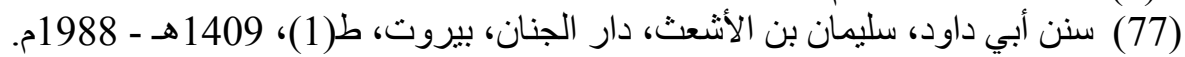

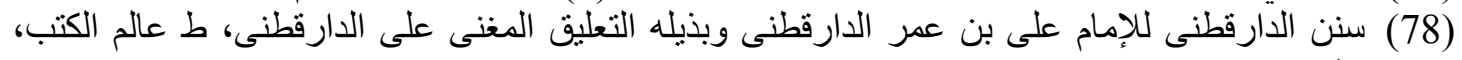

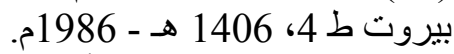

(79) سنن الدارمي للإمام أبي محمد عبد الله بن عبد الرحمن، ط 1، 1407هـ - 1987م، دار الكتاب العربي،

بيروت النين الكبرى، لأبى بكر أحمد بن الحسن بن علي البيهقي وبذيله الجوهر النقي، دار الفكر، بيروت،

(81) سير أعلام النبلاء، للذهبي، تحقيق: شعيب الأرنؤوط وآخرين، مؤسسة الرسالة، ط(3)، 1406هـ ـ

1986م.

\section{References}

1. Rejoicing in the statement of the terminology of the curriculum, Ahmed bin Abi Bakr bin Sumit Alaoui Hadrami, publisher, Committee of the Arab statement, 1960.

2. Alliance of the righteous gentlemen to explain the revival of the sciences of religion, for the mark, Mr. Mohammed bin Mohammed al-Husseini Zubaidi famous Mortada, House of Scientific Books, Beirut - Lebanon, 2005. 


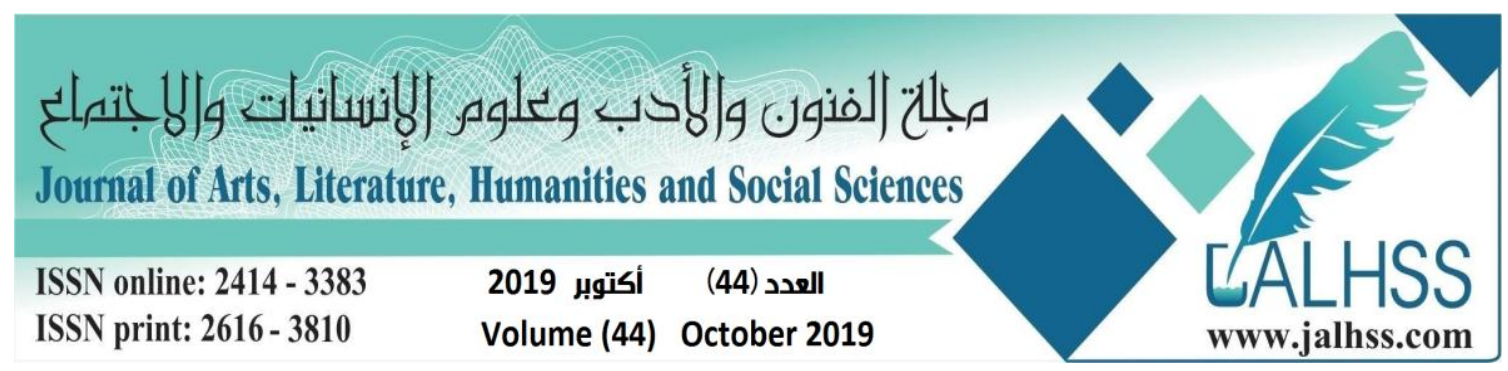

3. Tightness of Judgments Explanation of the mayor of judgments, Taqi al-Din Ibn Daqiq al-Eid, investigation: Mohammed Hamed al-Feki - Ahmed Mohammed Shaker, Sunna Mohammedia Press, Cairo, 1372 e - 1953

4. News of Mecca in the ancient and modern age, Abu Abdullah Mohammed bin Isaac bin Abbas al-Makki fruity (deceased: $272 \mathrm{e}$ ), investigation, d. Abdul Malik Abdullah Dahish, Dar Khader - Beirut, 1414 AH.

5. News of Mecca and its antiquities (Azraqi), Mohammed bin Abdullah bin Ahmed Azraqi, Abu Walid, investigation, Abdul Malik bin Abdullah bin Dahish, AlAsadi Library, Mecca, 1424 - 2004.

6. The choice of explanations for the chosen, Abdullah bin Mahmoud bin Mudood al-Musli al-Baladhi, Majd al-Din Abu al-Fadl al-Hanafi (deceased: 683 AH), with comments: Sheikh Mahmoud Abu minute (a Hanafi scholars and a teacher at the Faculty of the Fundamentals of the former), Halabi Press - Cairo - Egypt, $1356 \mathrm{H}$ $-1937$.

7. Guide Salik to the actions of the rites, Ibrahim bin Farhoun civil Maliki, the investigation Mohammed Abu Ajfan, the National Foundation for Translation, Investigation and Studies (House of Wisdom), Tunisia, 1989.

8. Guidance of the servants to the path of Rashad, Zainuddin Abdul Aziz AlMelibari. This is a book I elected from two books: Al-Zawajer, and the student's guide, by Shahab Al-Din Ahmad Bin Hajar Al-Hithmi, 2011

9. Asna demands in explaining the kindergarten student: Sheikh Islam Zakaria AlAnsari, investigation: Dr. Mohammed Mohammed Tamer, House of Scientific Books, Beirut, the first edition 1422 e - 2000.

10. References to the knowledge of visits, Abu Hassan Hassan bin Abi Bakr bin Ali Herawi, (deceased: 611 e), Library of Religious Culture, Cairo, i 1, 1423 e).

11. Originally known as al-Mabsut, Abu Abdullah Muhammad ibn al-Hasan ibn Farqad al-Shaibani (deceased: 189 AH), investigation, Abu al-Wafa al-Afghani, the Department of the Koran and Islamic Sciences - Karachi, 1410 AH-1990.

12. Flags, to Khair al-Din bin Mahmoud bin Mohammed bin Ali bin Faris Zarkali Damascus Deceased: 1396 e, House of science for millions, Beirut, 1986.

13. Hajj works, Abdullah bin Ahmed Allaf Al-Ghamdi, two parties for publishing and distribution - Taif, $1431 \mathrm{AH}$.

14. Mother, Shafi'i Abu Abdullah Mohammed bin Idris bin Abbas bin Othman bin Shafea bin Abdul Muttalib bin Abdul Manaf al-Muttalbi al-Qurashi al-Makki, (deceased 204 e), House of Knowledge - Beirut, 1410 e - 1990.

15. Genealogies, for the Sama'ani, Abdul Karim bin Mohammed bin Mansour Tamimi Samani Marwazi, Abu Saad (deceased: 562 e), investigation, Abdul Rahman bin Yahya al-Ma'alimani Yamani, Council of the Department of Ottoman knowledge, Hyderabad, 1382 e - 1962.

16. The Holy Lights in Personal Status, Abdul Karim Mohammed Al-Mudares, AlJahez Press, Baghdad, 1410H-1990G.

17. The clearest tract to the provisions of the rites, Abdul Aziz bin Mohammed Salman, 1409 e-1989. 


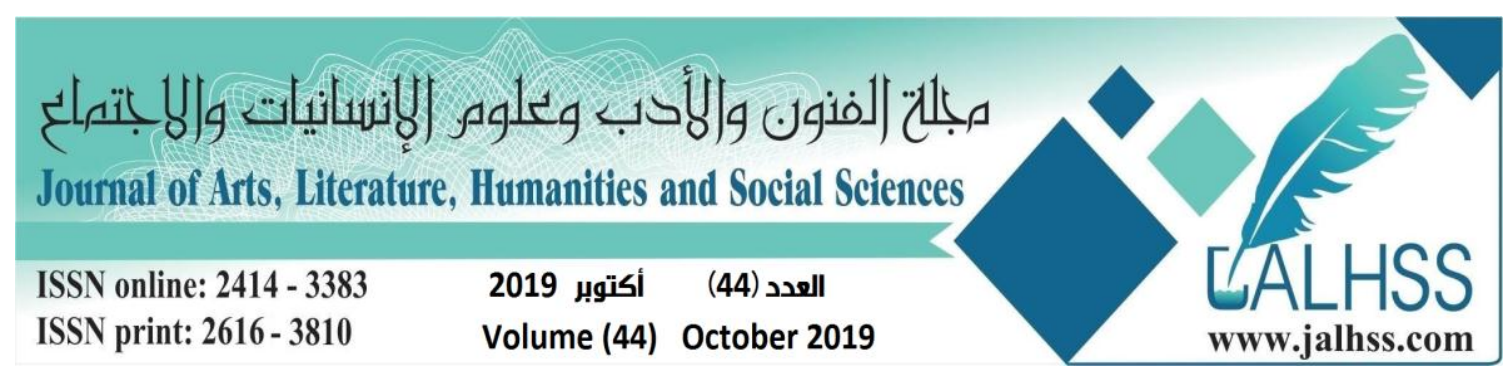

18. Clarification in the rituals of Hajj and Umrah, Abu Zakaria Mohiuddin Yahya bin Sharaf al-Nawawi (deceased: $676 \mathrm{AH}$ ), and therefore: Disclosure on the issues of clarification on the doctrines of the four imams and others to Abdul Fattah Hussein, Dar al-Bashaer Islamic, Beirut - Library Aldadip, Mecca, 1414 - 1994.

19. The beginning of the diligent and the end of the thrifty, to judge Abu Walid Mohammed bin Ahmed bin Mohammed bin Ahmed bin Rushd al-Qurtubi famous Ibn Rushd grandson (deceased: 595 e), Dar al-Hadith - Cairo, 1425 - 2004.

20. Badaa'i Sanayea in the order of canons, Abu Bakr bin Masood bin Ahmed AlKasani Hanafi Aladdin, House of scientific books, 1406 e - 1986.

21. Al-Bader coming in the aftermath of the seventh century, by Judge Allama Muhammad ibn Ali al-Shawkani (Tel: 1250 AH), Al-Saada Press, Cairo, first edition $1348 \mathrm{AH}$.

22. Building in explaining guidance, Abu Mohammed Mahmoud bin Ali al-Aini (Tel: 855 e), Dar al-Fikr, Beirut, second edition 1411 e - 1990.

23. Crown of the bride of the dictionary jewels, Mohammed bin Mohammed bin Abdul Razzaq Husseini, Abu Fayd, nicknamed Murtada, Zubaidi (died: 1205 e), investigation: a group of investigators, Dar Hedaya, 2010.

24. The history of Sulaymaniyah, by Mohammed Amin Zaki, printed in Baghdad $1370 \mathrm{AH} / 1951 \mathrm{AD}$.

25. History of Islamic jurisprudence d. Nasser Bin Aqeel Al-Tarifi, Library of Repentance, Riyadh, 2nd Floor, 1418 AH / 1997 AD.

26. History of Islamic Jurisprudence, by Muhammad Ali Sayes, Scientific Books House, Beirut - Lebanon, 2011.

27. The Great History of Al-Bukhari, Scientific Books House, Beirut, 2010.

28. History of the Kurds in Islamic Civilization, Dr. Ahmed Khalil, Dar Hero, Beirut, 2005.

29. History of Baghdad, Imam al-Hafiz Abu Bakr Ahmed bin Ali al-Khatib alBaghdadi, Scientific Book House, Beirut-Lebanon, 2004.

30. The history of Mecca, the Holy Mosque, the Holy City, and the Holy Sepulcher, Imam Abu al-Baqaa Mohammed bin Ahmed bin Mohammed bin Zia Makki Hanafi (d. 854 AH), investigation, Alaa Ibrahim Al-Azhari, Ayman Nasr AlAzhari, Scientific Books House, Beirut-Lebanon,1424 AH / 2004 AD.

31. Editing words alert, Abu Zakaria Mohiuddin Yahya bin Sharaf nuclear (deceased: 676 e), the investigation: Abdul Ghani Dagr, Dar al-Qalam - Damascus, 1408 e.

32. Masterpiece of the needy in explaining the curriculum, to Ahmed bin Mohammed bin Ali bin Hajar Hitmi, the Great Commercial Library in Egypt to its owner Mustafa Mohammed, 1357 e - 1983.

33. Investigation, Abu Zakaria Yahya bin Sharaf al-Nawawi al-Shafei, investigation, Adel Abdul-Mawjood - Sheikh Ali Moawad, publisher, Dar al-Jabal, Beirut Lebanon.

34. The ticket of preservation, Shams al-Din Abu Abdullah Mohammed bin Ahmed bin Osman bin Qaymaz Golden (deceased: 748 e), House of Scientific Books Beirut-Lebanon, 1419 e-1998. 


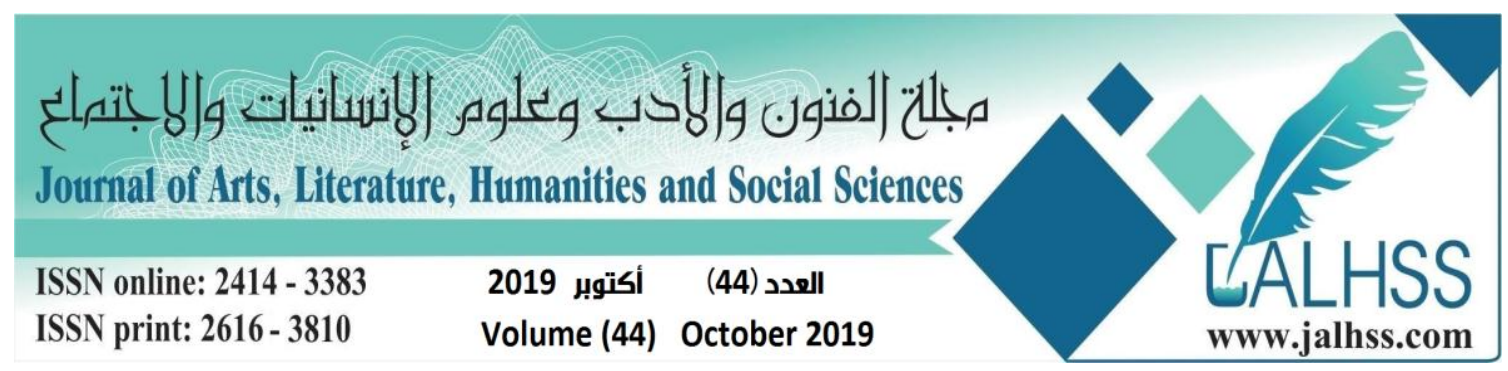

35. Arrangement of perception and approximation of the trajectories to know the flags of the doctrine of Malik, Abu al-Fadl judge Ayaz ibn Musa al-Hasbi (deceased: 544 e), printing press Fadala - Mohammedia, Morocco, 1983.

36. Facilitation of download science, Mohammed bin Ahmed bin Jazzi Kalbi Abu alQasim, investigation, Mohammed Salem Hashim, House of Scientific Books, Beirut, 1415 - 1995.

37. Definitions, Ali bin Mohammed bin Ali Zein Sharif Jurjani (died 816 e) House of scientific books - Beirut - Lebanon, 1983.

38. The Interpretation of the Great Quran (Tafseer Ibn Katheer), Ismail Ibn Omar Ibn Katheer Al-Qurashi Al-Damashi Abu Al-Fidaa Imad Al-Din, Investigation, Sami Bin Mohammed Al-Salamah, Dar Taibah, 2nd Floor, 1420H - 1999 AD.

39. Approximation of refinement, Abu al-Fadl Ahmed bin Ali bin Mohammed bin Ahmed bin Hajar Asqalani (deceased: 852 e), investigation, Mohammed Awama, Dar al-Rashid - Syrian, 1406 e - 1986.

40. Introduction to what is in the Muwatta of meanings and attributes, Abu Omar Yousef bin Abdullah bin Mohammed bin Abdul Barr bin Asim al-Nimri alQurtubi (deceased: 463 AH, investigation, Mustafa bin Ahmed al-Alawi, Mohammed Abdul Kabir al-Bakri, publisher, Ministry of General Endowments and Islamic Affairs - Morocco, $1387 \mathrm{H}$.

41. The refinement of names and languages, Abu Zakaria Mohiuddin Yahya bin Sharaf al-Nawawi (deceased: $676 \mathrm{AH}$ ), concerned with publishing, correcting, commenting and interviewing its origins: Al-Ulama with the assistance of the Illuminati Printing Department, Scientific Books House, Beirut - Lebanon.

42. The refinement of refinement, Abul Fadl Ahmed bin Ali bin Mohammed bin Ahmed bin Hajar Asqalani (deceased: 852 AH, Press Department of regular knowledge, India, the first edition, $1326 \mathrm{e}$.

43. The refinement of perfection in the names of men, to Abu Hajjaj Yousef Almazi, achieve: d. Bashar Awwad, Resala Foundation, Beirut, Lebanon, 1413 - 1992.

44. The refinement of the language, Al-Azhari, Mohammed bin Ahmed, investigation: Abdul Salam Haroun, Al-Khanji Library, Cairo, 1396 e - 1976.

45. Whole right «Sunan al-Tirmidhi», Abu Issa Mohammed bin Isa bin Surah, achieve: d. Bashar Awad Maarouf, Islamic House of the West, Beirut, 2nd floor, 1998.

46. The collection of mosques, to the judge of the judges Taj al-Din Abdul Wahab bin Ali al-Sobki, House of Scientific Books, Beirut-Lebanon, 1424 e-2003.

47. Efforts of Sheikh Abdulkarim jurisprudence teacher, to Dr. Abdullah Saeed Wissy Al-Kartaki, Mardin Press-Erbil,1433 AH-2012 AD.

48. Jawaher Fatwas Khair al-Zad in guidance, Abdul Karim Mohammed teacher, Press House optical - Baghdad, 1389 e - 1969.

49. A footnote to explain Al-Bjermi curriculum (abstraction for the benefit of slaves), Suleiman bin Mohammed Al-Bjermi, Press House of the Great Arabic Books Maymania - in Egypt, 1330. 


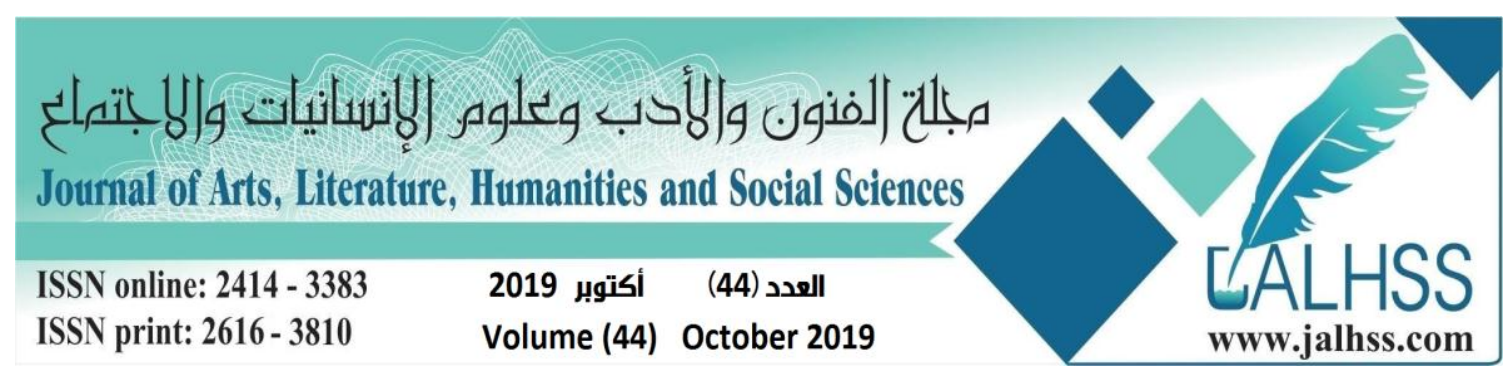

50. A footnote to the terminology - the term Al-Manhal Al-Manim with a footnote to the right curriculum - to explain the mark Ibn Hajar best introduction, to the world jurist Sheikh Mohammed Mahfouz bin Abdullah Al-Termasi, Dar AlManhaj, Beirut - Lebanon. 1432 AH-2011.

51. Footnote to the camel curriculum, to Suleiman bin Omar bin Mansour Ajili Egyptian, known as «camel», Dar al-Fikr - Beirut.

52. A footnote to El-Desouki on the great explanation, by Mohamed Arafa ElDesouki, Achievement by: Mohamed Alish, House of Arabic Books Revival, Cairo - Egypt, 2010.

53. A footnote to the ground box explaining increased al-Mustaqeen, Abdul Rahman bin Mohammed bin Qasim al-Asmi Najdi Hanbali, 1397 e.

54. Al-Adawi's footnote to explain the adequacy of the Lord's student, Abu al-Hasan, Ali bin Ahmed bin Makram al-Sa'idi al-Adawi (relative to Bani Uday, near Manfalut) (deceased: 1189 AH), investigation, Yusuf al-Shaykh Muhammad alBuqai, Dar al-Fikr, Beirut, 1414 - 1994.

55. A footnote to the scholar Ibn Hajar al-Hitmi to explain the explanation in the rituals of Hajj to the nuclear imam, for the mark Ahmed bin Mohammed bin Ali bin Hajar al-Hitmi Saadi al-Ansari Mecca 909 e - 974 e.

56. The footnote of the response of al-Muhtar to al-Dur al-Mukhtar (footnote of Ibn Abdeen) by the scholar Muhammad Amin, renowned as Ibn Abdeen, and complemented by the so-called "Korat Ayoun al-Akhyar".

57. Hashit Qalioubi and Omira to explain the local curriculum students, Ahmed Salama Qalioubi and Ahmed Berlosi Omira, Dar al-Fikr - Beirut, 1415 e-1995.

58. The great container in the jurisprudence of the doctrine of Imam Shafi'i, a brief explanation Mizni, Abu Hassan bin Mohammed bin Mohammed bin Habib alBasri Baghdadi, famous Balawardi (deceased: $450 \mathrm{AH}$ ), investigation, Sheikh Ali Mohammed Moawad - Sheikh Adel Ahmed Abdel Mawjoud, Scientific Books House, Beirut - Lebanon, 1419 - 1999.

59. Hassan Lecture, in the history of Egypt and Cairo, Jalal al-Din al-Suyooti, investigation: Mohammed Abu al-Fadl Ibrahim, 1387 AH - 1967, Dar revival of Arabic books, Issa al-Babi Halabi, Cairo.

60. Footnotes of the Curriculum Masterpiece Explanation of the Curriculum, by Imam Abdul Hamid Al-Sherwani - and Ibn Qasim al-Abadi, on the masterpiece of the needy son of Hajar al-Hitmi, the Great Commercial Library of Mustafa Mohamed in Egypt, 1357 AH - 1938 AD.

61. The life of the glories of the Kurdish scholars, by Sheikh Taher Mulla Abdullah al-Baharki, Dar Ibn Hazm, 1436 AH-2015, Beirut-Lebanon.

62. Summary of the Interpretation of the Developing, by Sheikh Abdul Karim Mohammed Al-Mudares, Al-Mashreq Press, Baghdad, 1st Floor, 1421H-2000G.

63. Durr al-Mukhtar explained the enlightenment vision and the collector of the sea, to Mohammed bin Ali bin Mohammed al-Husni known Ala al-Din al-Haskafi Hanafi (deceased: 1088 e), the investigation: Abdul Moneim Khalil Ibrahim, Scientific Books House, 1423 e - 2002. 


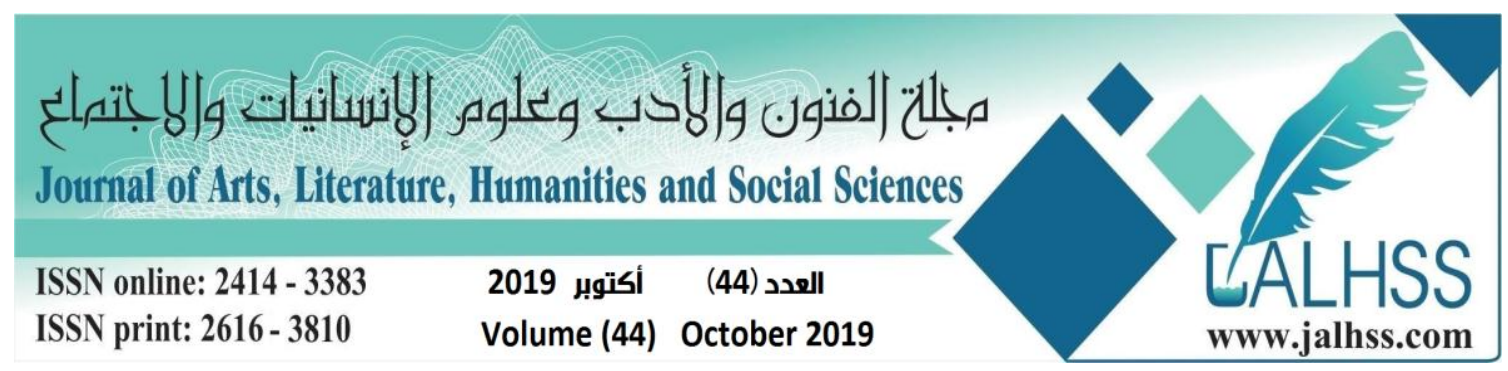

64. Durrs inherent in the objects of the eighth hundred, the son of Hagar Ashqlane Ottoman knowledge circle, Hyderabad, India,1349 AH.

65. Guide to the needy Explanation of the curriculum, Sheikh: Rajab Mohammed Nuri Mashwah, the comprehensive library, 2011.

66. The doctrine of the doctrine in the knowledge of the elders of the doctrine scientists, Ibrahim bin Ali bin Mohammed, the son of Farhoun, Burhanuddin alYamri (deceased: 799 e), investigation and commentary, Dr. Mohammed Ahmadi Al-Nour, House of Heritage for Printing and Publishing, Cairo, 2011.

67. The confused response to Al-Dur Al-Mukhtar (footnote Ibn Abdeen), to Ibn Abdeen, Mohammed Amin bin Omar bin Abdul Aziz Abdeen Damascene Hanafi (deceased: 1252 e), Dar al-Fikr-Beirut, 1412 e - 1992.

68. Letter in the ruling on the line adjacent to the Black Stone, Nasser bin Hamad AlFahad, 1418 e.

69. Messages of Mercy in Logic and Wisdom, by Sheikh Abdul Karim Mohammed Al-Mudares, Dar Al-Arabia, Cairo, 1979.

70. Letters of gratitude in exchange, grammar, status and statement, by Sheikh Abdul Karim Mohammed teacher, Arab House - Baghdad, 1978.

71. Roskari Zianem (days of my life), by Sheikh Abdul Karim Mohammed teacher, Kurdistan Press, Sanah, Iran, 2013.

72. Al-Rawdah Al-Murabba Explanation of Zad Al-Mustaqeen - Summary of AlMajeen - by Imam Mansour Bin Younis Al-Bohouti, Scientific Books House, Beirut, Eighth Edition

73. Kindergarten students and mayor of muftis, Abu Zakaria Yahya bin Sharaf nuclear, the investigation of Adel Abdul Mawjood and Ali Mohammed Moawad, House of Scientific Books, Beirut - Lebanon, 1425 - 2005.

74. Site, (Encyclopedia of Saudi Arabia) www.saudiency.net.

75. Ways of Peace Explanation of attainment of the provisions of the provisions of the judgments, Mohammed bin Ismail Prince Sanani, investigation, Mohammed Nasser al-Din Albani, Library of Knowledge, Beirut - Lebanon, 1427 e - 2006.

76. Sunan Ibn Majah, to Hafiz Abu Abdullah Mohammed bin Zaid al-Qazwini, investigation: Bashar Awad, Dar generation, Beirut, 1418 - 1998.

77. Sunan Abu Dawood, Suleiman ibn al-Ash'ath, Dar al-Jinan, Beirut, I (1), 1409 e 1988.

78. Sunan Aldarqotni Imam Ali bin Omar Aldarqotny and his footer singer commentary on Aldarqotny, i world of books, Beirut, 1406 e - 1986.

79. Sunan al-Darami of Imam Abu Muhammad Abdullah bin Abdul Rahman, 1407 AH - 1987 AD, the Arab Book House, Beirut.

80. Great Sunan, Abu Bakr Ahmed bin Hassan bin Ali al-Bayhaqi and its tail pure essence, Dar al-Fikr, Beirut, 1985.

81. Biography flags of the nobles, for the golden, investigation: Shoaib Arnaout and others, the message Foundation, 1406 e - 1986. 